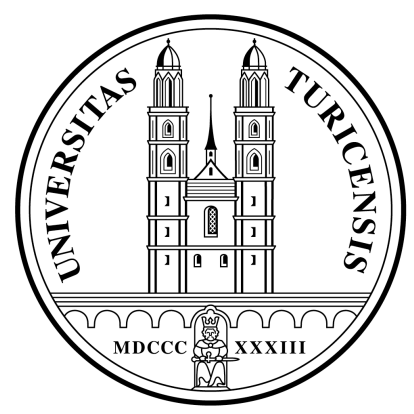

Institute for Empirical Research in Economics

University of Zurich

Working Paper Series

ISSN 1424-0459

Working Paper No. 38

Contractual Incompleteness and the Nature of

Market Interactions

Martin Brown, Armin Falk and Ernst Fehr

February 2002 


\title{
Contractual Incompleteness and the Nature of Market Interactions
}

\author{
Martin Brown, Armin Falk, Ernst Fehr* \\ University of Zurich
}

February 2002

\begin{abstract}
We provide experimental evidence that contractual incompleteness, i.e., the absence of third party enforcement of workers' effort or the quality of the good traded, causes a fundamental change in the nature of market interactions.

If contracts are complete the vast majority of trades are initiated by public offers. Most trades take place in one-shot transactions and the contracting parties are indifferent with regard to the identity of their trading partner. Moreover, the short side of the market attempts to appropriate the whole gains from trade, which causes much disagreement about contract terms.

If contracts are incomplete the vast majority of trades are initiated by private offers. The contracting parties form long-term relations and the provision of low effort or bad quality is penalized by the termination of the relationship. The threat of terminating the relation turns out to be an extremely powerful discipline device. Markets with incomplete contracts resemble a collection of bilateral trading islands rather than a competitive market. The short side of the market shares the gains from trade with the long side of the market so that there is little disagreement about contract terms.
\end{abstract}

Our results support theories of the labor market that are based on the idea that unemployment is a worker discipline device.

JEL: D2, D4, C7, C9

Keywords: Market Interaction, Contract Enforcement, Incomplete Contract, Involuntary Unemployment, Repeated Transaction, Fairness Preferences

* Institute for Empirical Research in Economics, University of Zurich, Blümlisalpstrasse 10, CH-8006 Zürich, falk@iew.unizh.ch, efehr@iew.unizh.ch. Financial support by the Swiss National Science Foundation (Project No. 1214-05100.97), by the MacArthur Foundation (Network on Economic Environments and the Evolution of Individual Preferences and Social Norms), is gratefully acknowledged. This paper is also part of the EU-TMR Research Network ENDEAR (FMRX-CTP98-0238). We also thank D. Abreu, R. Benabou, S. Bowles, A. Dixit, U. Fischbacher, O. Hart, B. Holmström, G. Loewenstein, E. Maskin, A. Rubinstein, K. Schmidt, A. Schotter, C. Zehnder, the participants at the ESA-meeting in New York, of research seminars at the Free University in Berlin, at the Tinbergen Institute in Amsterdam, at Harvard-MIT, at Princeton and New York University and at the European Summer Symposium on Economic Theory in Gerzensee for helpful comments and discussions. 


\section{Introduction}

In many markets transactions are based on incomplete contracts allowing for considerable discretion. The prime example for a market with incomplete contracts is the labor market but other markets with complex products - like e.g., the market for customer-tailored software - are also characterized by contractual incompleteness. In these markets important elements of the contracts are described in a very imprecise manner and third parties are, in general, unable to verify whether the parties did or did not meet their obligations. Therefore, the contracting parties face serious enforcement problems. ${ }^{1}$ In the past two decades there has been considerable theoretical progress in the analysis of markets with enforcement problems with a strong focus on repeated interactions (see e.g., Gintis 1976, Klein and Leffler 1981; Shapiro and Stiglitz 1984; Bowles 1985; Bull 1987; Hart and Holmström 1987; MacLeod and Malcomson 1989, 1993 and 1998; Baker, Gibbons and Murphy 1994; Dixit 2001). However, in contrast to the progress of theory empirical evidence has been sparse. While lack of empirical knowledge is always problematic, in our context this lack is even more serious because in the presence of repeated interactions there is, in general, a plethora of equilibria (see e.g., Fudenberg and Maskin 1986). For this reason theory alone gives us little guidance regarding the likely consequences of enforcement problems for the functioning of markets.

In this paper we show experimentally that contractual incompleteness causes fundamental changes in the nature of market interactions. Our experiments indicate that in markets with complete contracts, i.e., where the effort or the quality of the good traded is exogenously enforced by third parties, the traders are basically indifferent with whom they trade - the identity of the trading partner does not matter. As a consequence, the vast majority of trades take place in one-shot transactions. Most offers in these markets are public offers that can be accepted by any trader on the other side of the market. In addition, there is much disagreement about the contract terms because the short side of the market attempts to appropriate almost the whole gains from trade. $^{2}$

In contrast, in markets with incomplete contracts, where effort is not enforceable by third parties, the traders are very much concerned about the identity of the trading partner. They endogenously establish bilateral long-term relations and the predominant pattern is repeated trading with the same trading partner over extended periods of time. The workers in this market

\footnotetext{
${ }^{1}$ The emphasis in this paper is on contractual incompleteness that is associated with the absence of third party enforceability of contracts terms. There are, of course, other forms of contractual incompleteness, which are, however, not the object of our study. Our paper is also not concerned with the impact of contractual incompleteness on vertical integration (on this question see Grossman and Hart 1986; Hart 1995).

2 Although we believe that our results are relevant for labor markets as well as for goods markets, to ease the exposition in the following we present our results in labor market terms.
} 
are disciplined by the threat of firing. We show that this threat is an extremely powerful discipline device. If firms and workers can voluntarily form and terminate repeated trading relations the majority of effort choices is at or close to the maximum. In sharp contrast, if we rule out the possibility of repeated trading relations in an incomplete contracts market the majority of effort choices is at or close to the minimum. These results neatly complement econometric studies indicating that the cost of job loss have been an important determinant of U.S. productivity growth (Bowles, Gordon and Weisskopf 1983).

The long-term relations between firms and workers are established by private offers to those workers who performed well in the previous transaction. Over time the market with incomplete contracts becomes thoroughly permeated by bilateral relations. Firms voluntarily constrain the set of trading partners by addressing their offers to a specific worker and most of the offers are immediately accepted so that there is little disagreement about the terms of the contract.

Our results lend support to the disciplining version of the efficiency wage hypthesis (Gintis 1976, Shapiro and Stiglitz 1984, Bowles 1985) as well as to the fairness version of the efficiency wage hypothesis (Akerlof 1982, Akerlof and Yellen 1990). The disciplining version is based on the idea that the payment of rents in combination with the threat of firing constitutes a discipline device for the workers and gives rise to involuntary unemployment. In a series of papers MacLeod and Malcomson $(1989,1993,1998)$ pointed out that - in the presence of an effort enforcement problem - the equilibrium with rents and involuntary unemployment is only one of infinitely many equilibria and that the Walrasian outcome with no rents and no involuntary unemployment is also an equilibrium. In Malcomson (1999) as well as MacLeod and Malcomson (1998) the authors argued, however, that if fairness concerns affect players' beliefs Non-Walrasion outcomes will emerge. Our results indeed show that the market outcome in the incomplete contracts condition is Non-Walrasian. Moreover, the behavioral patterns suggest that this is due to the existence of fairness concerns.

Both in the experimental condition with complete and with incomplete contracts we have an excess supply of workers. In the market with complete contracts the firms take advantage of this excess supply by enforcing contract terms that give the workers little more than their reservation payoffs. In the market with incomplete contracts the situation is very different. Despite their being in excess supply, workers earn generous rents and firms make no attempts at extracting these rents. The reason for this is the presence of a sizeable fraction of fair-minded workers who respond to less generous contract offers with lower effort levels. The presence of fair-minded workers thus prevents firms from extracting future rents by low current offers. It 
seems that the firms' contract offers are largely determined by their attempts at solving the effort enforcement problem and that competition has little influence on the contract terms. In addition, shirking workers face a high probability of firing in case of low effort, exactly as it is predicted by the disciplining approach of efficiency wage theory.

Several of our results on the bilateralization of markets can also be viewed as an example of Williamson's (1985) fundamental transformation. ${ }^{3}$ Williamson forcefully argued that - in the presence of relation-specific investments - trading relations that are ex-ante subject to outside competition become ex-post insulated from outside competition. Due to relation-specific investments the parties can create higher gains from trade if they stay together than if they separate, inducing a bilateralization of the relation and a weakening of the impact of outside competition on the terms of trade. In our experiment workers invest in their reputation as trustworthy trading partners. This reputation has value only in the worker's current trading relation because solely his firm knows his effort. Thus, a worker's reputation as a trustworthy person can be viewed as a relation-specific asset. Since the firm can never be completely sure whether an alternative worker will be equally trustworthy it has an incentive to stay with the same worker in case that the worker has performed well in the past.

Several aspects of our data suggest that relation-specific reputational assets contribute to the existence of long-term relations. Firms, for instance, expect higher effort levels from their workers the longer the relationship between the worker and the firm has already lasted. In addition, the uncertainty with which firms expect a given effort level also increases with the length of the relationship. Moreover, the workers' actual effort does indeed increase with the length of the relationship. This indicates that the value of an employment relation increases with the length of the relation because the effort rises and becomes less uncertain the longer the relation lasts. Therefore, if firms are aware of this, we should also observe that firms are - ceteris paribus - more reluctant to fire workers with whom they transacted more often in the past. It turns out that this is indeed the case.

There are also "methodological" returns from our research. In all of our experiments we implemented a finite and commonly known time horizon. In the past the theory of repeated games has sometimes been criticized by pointing out that in order to sustain self-enforcing agreements an infinite time horizon has to be assumed. For instance, Hart (2001) recently argued that this "is hard to square with the fact that people have finite lives." However, our short

\footnotetext{
${ }^{3}$ Our empirical results are also reminiscent of the paper by Rubinstein and Wolinski (1990). These authors show that if the traders in a pair-wise matching and bargaining environment condition their strategies on the identity of their trading partner and on past events, non-competitive outcomes may result even if frictionless bargaining is possible.
} 
theoretical discussion in section 3 and our empirical results suggest that this is too pessimistic a view because in the presence of a substantial fraction of fair-minded agents the scope for selfenforcing agreements is greatly enhanced. Despite the existence of a finite horizon the trading parties in our experiment are in fact able to form long-term relations and to enforce effort levels far above what can be enforced in one-shot interactions. This shows how the enforcement capabilities arising from the possibility of forming finite long-term relations are greatly enhanced by the presence of fair-minded agents. ${ }^{4}$

We also believe that our experimental design can be used as a "work horse" for the study of many interesting and empirically unresolved questions. They provide the basis for examining the interaction between implicit and explicit incentives as, for instance, theoretically discussed in Baker, Gibbons and Murphy (1994) or Schmidt and Schnitzer (1995). In addition, it is possible to analyze the effects of contract termination laws or of stigma effects arising from unemployment. Likewise, questions regarding the role of relational contracts in vertical integration decisions (Baker, Gibbons and Murphy (2002) can be usefully pursued in our experimental framework.

The rest of the paper is structured as follows. In the next section we discuss the specific advantages of laboratory experiments for answering our core questions. This section also presents the experimental design. In Section 3 we discuss the theoretical predictions. In Section 4 we present and interpret our results and Section 5 concludes the paper.

\section{An Experimental Approach for the Study of Markets with Incomplete Contracts}

The ideal data set for studying the effects of lacking third party enforceability on market interactions and on the firms' enforcement strategies is based on a truly exogenous ceteris paribus variation in the degree of third party enforceability. The exogenous ceteris paribus variation allows the researcher to make causal inferences regarding the impact of different degrees of third party enforceability. With such a data set it is, for instance, possible to examine how the absence of third party enforceability affects the initiation of contracts in markets, the formation of long-term relations or the level of wages and contract terms in general. The

\footnotetext{
${ }^{4}$ In theory similar ideas have been around for a long time (see, e.g., Kreps et al. 1982). What we add is that because of the empirical existence of fair-minded types endogenous long-term relations can be part of an equilibrium although there is a finite horizon.
} 
problem is, however, that it seems almost impossible to find or generate field data that come close to this ideal data set:

First, there are huge measurement problems involved in answering our questions. It is, for example, very difficult to construct a convincing index of the degree of third party enforceability in the field because this variable depends on many subtle details in the law and the legal practices of the courts. Likewise, it is extremely difficult to find convincing measures of the firms' effort requirements, the workers' actual effort or the job rents. Job rents are insofar important for answering our questions as in long-term relations the payment of job rents combined with the threat of firing might be an effective effort enforcement strategy. Yet, as the debate on the nature of inter-industry wage differentials indicates it is far from obvious whether workers in a particular industry, or in particular firms, do indeed earn job-rents, not to speak of precise measures for the job rents (Krueger and Summers 1988; Murphy and Topel 1990; Gibbons and Katz 1992).

Second, in reality there are many other reasons, beyond the absence of third party enforceability, that may cause long-term relations between trading parties and it seems almost impossible to control for all these other reasons. Subtle and, therefore, unobservable forms of asset specificity (e.g., firm-specific human capital) may cause long-term relations. There may be legal differences across industries and countries or unobservable differences in unwritten, yet powerful, business norms. Search and mobility costs, as well as exogenous uncertainty, may differ in unobservable ways across firms and industries confounding the impact of third party enforceability, even if that variable could be measured appropriately.

Third, many of the interesting variables are determined simultaneously causing difficult endogeneity problems. It seems quite plausible that the actual degree with which the trading parties govern their activities by less than complete contracts is also shaped by the effectiveness of alternative governance mechanisms like, e.g., long-term implicit contracts. Yet, this means that contractual incompleteness does not only affect the parties' long-term relations but that the effectiveness of long-term relations as an enforcement device also affects the parties' willingness to leave contracts incomplete. On the basis of the usually available field data it seems almost impossible to disentangle these effects.

In view of the severe difficulties created by the characteristics of field data it is not surprising that only few econometric studies of markets with enforcement problems have been conducted. McMillan and Woodruff (1999) examine the determinants of trade credits for customers in Vietnam's emerging private sector. Contract law and the courts provide only weak enforcement of agreements in Vietnam so that it seems plausible that the trading parties rely on 
relational contracts. McMillan and Woodruff provide interesting evidence showing that firms are more likely to offer trade credit if (i) the customer has difficulties finding an alternative supplier, (ii) the longer the trading relationship has already lasted, and (iii) the more the customer is integrated into business networks. Banerjee and Duflo (2000) analyze the role of reputation in determining contractual outcomes in the Indian software industry. Their results show that ex-ante contracts, as well as the bargaining outcomes after ex-post renegotiation of the contracts, vary with those firm characteristics that are plausibly associated with reputation. These studies constitute important steps forward in the empirical analysis of relational contracts. ${ }^{5}$ Yet, on the basis of the data used in these studies it seems impossible to make causal inferences regarding the impact of third party enforceability on market interactions and contract terms.

In view of the limitations imposed by field data an experimental approach for answering our core questions may provide important additional insights. The power of an experimental approach stems from the fact that measurement and endogeneity problems as well as the problem of controlling for other factors contributing to long-term relations can be avoided with a single stroke: In the laboratory it is no problem to implement an exogenous ceteris paribus variation in the degree of third party enforceability.

\subsection{Experimental Design}

To examine the consequences of contractual incompleteness we implemented the following three treatment conditions. In the first condition, which we call the complete contract condition $(\mathrm{C}$ condition), the contractually agreed upon effort level was exogenously enforced by the experimenter. In the second condition, which we call the incomplete contract condition (ICFcondition), the worker could choose any feasible effort irrespective of the contractually agreed upon level. Both in the C- and in the ICF-conditions firms and workers had the possibility of entering into long-term relations. Technically, repeated transactions with the same trading partner were possible because subjects had fixed identification (ID) numbers and contract offers could be addressed to specific traders (i.e., specific ID numbers). ${ }^{6}$ Therefore, a firm could make offers to the same worker in consecutive periods and, if the worker accepted the offers, a longterm relation was established. By comparing market interactions and contract terms across the Cand the ICF-condition our major research questions can be examined.

In addition we were also interested in the effectiveness of endogenous long-term relations as an effort enforcement device. Therefore, we implemented a third treatment, which we call the

\footnotetext{
${ }^{5}$ The paper by Crocker and Reynolds (1993) examines the determinants of contractual incompleteness. The focus is thus quite different compared to the studies of McMillan and Woodruff (1999) and Banerjee and Duflo (2000).
} 
ICR-condition. The ICR-condition is identical to the ICF-condition except that in the ICRcondition long-term relations were ruled out. This was achieved by randomly reassigning the ID numbers for both the workers and the firms in each period of the game - hence the term ICR

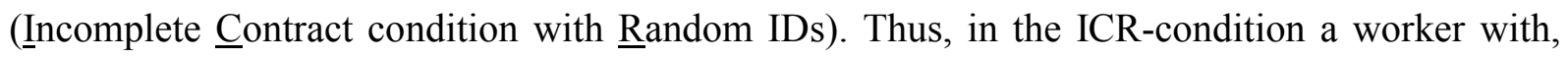
say, ID No. 8 in period $t$ may have been assigned ID No. 3 in period $t+1$, etc.. Since in the ICR no long-term relations were possible a comparison between the effort in the ICR and the ICF tells us to what extent the possibility of forming and terminating long-term relations contributed to the enforcement of more efficient effort levels. This comparison is important because we know from several other experiments (e.g., Fehr, Gächter and Kirchsteiger 1997) that fairness concerns may contribute to contract enforcement. This means that even in the absence of any possibility for long-term relations non-minimal effort levels may be achieved by making generous contract offers to the workers because fair workers increase their effort levels in response to wage increases.

In all the conditions there were 15 trading periods and in each period a firm could employ at most one worker and a worker could accept at most one job. A trading period had two stages. At stage one contract offers were made and, if a firm and a worker concluded a contract, they entered the second stage. At the second stage of the ICF- and the ICR-condition the worker had to determine his effort level. In the C-condition the computer automatically fixed the effort level at the contractually agreed upon level. During the second stage of the ICF- and the ICRcondition we also asked the firms to indicate an expected effort level and how certain they were that their expectations would come true.

In all conditions the firms were the contract makers, i.e., they could make contract offers to the workers. Workers could not make offers to the firms. A contract offer stipulated a wage $w$, a desired effort $\widetilde{e}$ and the identification (ID) number of the firm. Firms could make private or public offers. In case of a private offer, the firm also indicated the ID number of the worker with whom it wanted to trade and then only this worker was informed about the offer. In case of a public offer all workers and firms were informed about the offer. As a consequence, all workers could accept a public offer.

In a given trading period a firm could make as many private and public offers as it wanted to make. However, as soon as a worker accepted one of the offers, the firm was matched with this worker and informed about the ID number of the worker. Once a firm's offer was accepted all its other outstanding offers were immediately removed from the market so that they were no longer available. At any time during a trading period firms were also informed about

\footnotetext{
${ }^{6}$ Hence, ICF means Incomplete Contract Condition with Fixed IDs.
} 
which workers were still in the market. This was done to prevent firms from making private offers to workers who had already concluded a contract with somebody else.

Both in the C-and in the ICF-condition the status quo at the beginning of each period was that no worker had a job and no firm had its vacancy filled. Alternatively, we could have implemented the rule that a firm-worker relation automatically continues to hold unless one of the parties quits. Economically these two rules are equivalent if the parties are free to quit at the end of each period. Due to status quo effects (Samuelson and Zeckhauser 1988), however, the two rules may well have different behavioral effects. In our case the parties have to take actions to continue the relationship. The alternative rule calls for taking actions to dissolve the relationship. Therefore, status quo effects favor the formation of long-term relations under the alternative rule whereas our rule tends to weaken these effects. This means that our rule is less favorable to the emergence of long-term relations, making the actual emergence of long-term relations a stronger result.

Some aspects of our experimental design are similar to the design in Kollock (1994) and in Kirchsteiger, Niederle and Potters (2001). Both of these papers also allow the traders to make private and public offers and to form long-run relations. The focus of both papers is, however, quite different. Kirchsteiger, Niederle and Potters (2001) examine the role of private and public offers exclusively in a context with complete contracts while our work focuses on how private or public offers are used to support enforcement strategies in the presence of a moral hazard problem. In Kollock (1994) the sellers fixed the actual quality of their goods before the start of a trading period but they were free to make false claims about the quality of the good. Kollock observes that quality uncertainty contributes to the formation of long-term relationships. The most important difference between Kollock's work and ours is that we examine how the absence of third party enforcement affects contract terms and whether this leads to involuntary unemployment, how the contract terms are related to the firms' enforcement strategies and to what extent the possibility of forming long-term relations enhances effort. In Kollock (1994) these features are absent. ${ }^{7}$

\footnotetext{
${ }^{7}$ We parametrize the experiment such that there is a unique competitive equilibrium (with selfish preferences) while in Kollock - due to overlaps between supply and demand curves - every feasible price level that generates nonnegative profits constitutes a competitive equilibrium. This makes it impossible to detect Non-Walrasion outcomes because every division of the gains from trade is a Walrasian outcome. In addition, we implemented a finite horizon while Kollock did not tell the subjects how long the experiment would take. Thus he lost control over the subjects' perceived time horizon. Another important difference is that in our experiments workers chose their effort level after they had been employed at a certain wage. This means that we examine ex-post opportunism while Kollock studies ex-ante opportunism. In our set-up the effort level could thus respond to the wage level within a given period. In Kollock's set up sellers could not reciprocate high price offers in this way.
} 


\subsection{Parameters, Procedures, Information Conditions and Subject Pool}

In all three conditions we always had ten workers and seven firms, i.e., there was an excess supply of three workers. The material payoff of a firm was given by

$$
\pi_{f}= \begin{cases}10 \cdot e-w, & \text { if a contract was concluded } \\ 0, & \text { if no contract was concluded }\end{cases}
$$

The material payoff of a worker was given by

$$
\pi_{w}= \begin{cases}w-c(e), & \text { if a contract was concluded } \\ 5, & \text { if no contract was concluded }\end{cases}
$$

where $c(e)$ denotes the cost of supplying effort. ${ }^{8}$ The unemployment benefit of a worker who did not trade was 5 . The set of feasible effort levels was given by $\{1,2, \ldots, 10\}$ and wages had to be in the set $\{1,2, \ldots, 100\}$. The cost schedule for the workers is depicted in Table 1. It shows that $c(e)$ is strictly increasing and exhibits increasing marginal costs. Since the marginal cost of effort is at most 3 while the marginal revenue is always 10 , the efficient effort level is given by $e=10$.

TABLE 1: Cost of effort schedule

\begin{tabular}{ccccccccccc}
\hline \hline effort & $\mathbf{1}$ & $\mathbf{2}$ & $\mathbf{3}$ & $\mathbf{4}$ & $\mathbf{5}$ & $\mathbf{6}$ & $\mathbf{7}$ & $\mathbf{8}$ & $\mathbf{9}$ & $\mathbf{1 0}$ \\
\hline $\cos t$ & 0 & 1 & 2 & 4 & 6 & 8 & 10 & 12 & 15 & 18
\end{tabular}

In the ICF- and the ICR-treatment firms had to indicate (i) the effort level they expect in the current trade and (ii) the uncertainty of their effort expectation. They indicated their uncertainty by choosing a number in the set $\{1,2, \ldots, 7\}$ where 1 represented complete uncertainty and 7 complete certainty. Both the expected effort level and the uncertainty of their expectation had to be indicated after the contract was concluded but before the actual effort was revealed to the firm.

\footnotetext{
${ }^{8}$ The experimental instructions were framed in a neutral goods market language. The reason for this was that most subjects know that in the labor market long-term relations are pervasive. Therefore, we thought that long-term relations emerge more easily if the experiment is framed in labor market terms. Thus, if long-term relations emerge in the context of a goods market frame we have a stronger result. Translated instructions for the ICFtreatment are presented in Appendix 2.
} 
The payoff functions (1) and (2), the number of firms and workers, the cost schedule $c(e)$ and the fact that there were 15 trading periods were common knowledge. Only the pair of involved traders was informed about the actual payoffs and effort levels in the ICF and the ICR condition. In the course of a trading period each firm was also continuously informed about the public offers of the other firms. Similarly, a worker did not only know all the private offers addressed to him but also knew the public offers available.

The experiment was computerized and conducted by using the software "z-tree" (Fischbacher 1999). In each condition the experiment lasted for 15 trading periods. The decisions in these periods had monetary consequences. To make the participants familiar with the bidding procedures there were also two additional practice periods before the actual experiment. In both practice periods subjects only went through the first (bidding) stage of the experiment and no money could be earned during these periods. ${ }^{9}$ At the end of each of the 15 paid trading periods each participant was informed about the contract $(w, \widetilde{e})$ he or she had concluded, about $e$, their own payoff, the payoff of the trading partner and the ID number of the trading partner. Then the participants wrote this information on a separate sheet of paper. This procedure ensured that each participant was always fully informed about his or her own trading history.

In total 238 subjects participated in our experiments. We conducted five sessions in the ICF-condition, five sessions in the C-condition and four sessions in the ICR-condition. No subject participated in more than one session. A session lasted, on average, 90 minutes. Subjects were students from the University of Zurich and the Federal Institute of Technology in Zurich. On average, a subject earned CHF $62.3(\sim \$ 42$ at that time) in an experimental session.

\section{Predictions}

For the predictions it is crucial that all participants know that the experiment will end right after period 15. In case that rationality and selfishness of all participants is common knowledge, it is easy to derive a solution: In each period of the ICR and in the final period of the ICF each worker will choose the minimal effort $e=1$ irrespective of the accepted contract (w, $\widetilde{e})$. Therefore, contract offers with $w=5$ are optimal for the firms. ${ }^{10}$ All seven contract offers will be accepted. By backward induction the same outcome will be obtained in all previous periods of

\footnotetext{
${ }^{9}$ Since the practice periods did not involve any payments the workers would have had no real effort costs in these periods. This would have allowed them to fool the firms with regard to their true willingness to provide effort. To prevent this we did not conduct the second stage in the practice periods.

10 Since $w$ had to be an integer, $w=6$ is optimal if $w=5$ is rejected by the workers. For empirical purposes this difference is, however, negligible.
} 
the ICF. Thus in the ICF and the ICR condition a very inefficient outcome will be obtained and the resulting small surplus per trade, $\pi_{f}+\pi_{w}-5=(10 \cdot 1-5)+(5-0)-5=5$, will be reaped by the firms.

In the $\mathrm{C}$-condition the experimenter enforces every feasible effort level, i. e., also the maximum effort $e=10$. At $e=10$ the workers have opportunity costs of $5+c(10)=23$. Therefore the profit maximizing contract offer in $t=15$ is $w=23$ and $\widetilde{e}=10$. In equilibrium, all workers will accept this offer. ${ }^{11}$ In the C-condition the total surplus is given by $100-23=77$ which, in equilibrium, is again fully reaped by the firms in each of the 15 periods. Thus, if rationality and selfishness of all participants is common knowledge we should observe $w=5, e=$ 1 and 7 trades in all periods of the two incomplete contract conditions, whereas in the Ccondition $w=23, e=10$ and 7 trades should be observed in every period. Moreover, in all three conditions the firms should be indifferent between making private and public offers because selfish workers will accept any offer that gives them a positive payoff. This also means that we should observe no systematic differences in the share of private offers across treatments. Finally, there is also no reason for any party to engage in long-term relations. Nothing can be gained by entering a long-term relationship because in the incomplete contract conditions the effort will be minimal in any case while in the C-condition it will be $e=10$ even in a short term encounter. Thus there should be no systematic differences in the relative frequency of long-term relations across the $\mathrm{C}$ - and the ICF-condition.

If, however, rationality or selfishness of all traders is not common knowledge very different outcomes may occur because reputation building may become profitable ${ }^{12}$. If, for example, the firms in the ICF condition believe that there are sufficiently many fair types among the workers, it may be possible to sustain non-minimal effort levels for many periods in the ICF condition. Fair players respond to friendly actions in a friendly manner and they retaliate in response to hostile actions even when these responses are costly for them. These friendly and hostile responses also prevail in one-shot situations. ${ }^{13}$ Thus, fairness means that an increase in the generosity of a contract offer is reciprocated by an increase in the effort level even in a pure one-shot transaction. In our context the generosity of the contract offer can be measured by the current rent, $\pi_{W}(w, \widetilde{e})-5=w-c(\widetilde{e})-5$, that is implied by the offer. It is well known from

\footnotetext{
${ }^{11}$ Since $w$ had to be an integer there is also an equilibrium at $w=24$.

${ }^{12}$ For a model of reputation building see, e.g., Kreps et. al (1982).

${ }^{13}$ See Rabin (1993) for this definition of reciprocal fairness. Recently several new models of social preferences have been developed that are consistent with reciprocal responses in one-shot interactions (Levine 1998, Dufwenberg and Kirchsteiger 1999, Falk and Fischbacher 1999, Fehr and Schmidt 1999, Bolton and Ockenfels 2000, Charness and Rabin 2000). For the purposes of this paper it is not necessary to go into the details of the motives that may generate reciprocal responses. For our purposes it is important that a fraction of the subjects exhibits reciprocal behavior in one-shot interactions while the precise source of this behavior does not interest us here.
} 
numerous experiments that many people do in fact have a propensity to behave in a reciprocally fair manner in one-shot encounters (see, e.g., Camerer and Thaler 1995, Roth 1995, Fehr and Gächter 2000, Camerer forthcoming).

In Appendix 1 we use the model of Fehr and Schmidt (1999) to show that - in the presence of sufficiently many fair subjects - there is an equilibrium in the ICF in which all the workers provide non-minimal effort levels in the first 14 periods while in period 15 only the fair types perform at non-minimal levels. ${ }^{14}$ We also show that in the ICF higher average effort levels can be enforced in equilibrium than in the ICR because of the possibility of forming long-term relations in the ICF. The key mechanism in our argument is the existence of a positive rent for the workers in the final period of the ICF. A rent exists if a worker with a job earns strictly more than a worker without a job. In our context the rent is generated by the existence of fair workers. Since they respond to generous contract offers with generous effort levels they make it profitable for the firms to pay rents in the final period. Due to this rent it is possible to discipline the selfish workers in the first 14 periods, i.e., the selfish workers mimic the behavior of the fair workers so that their type is not revealed in the first 14 periods. ${ }^{15}$

If workers earn a positive rent in the final period of the ICF condition the threat to terminate the trading relation at the end of period 14 induces a selfish worker to bear positive effort costs in period 14. As long as the effort $\operatorname{cost} c(\widetilde{e})$ are below the expected rent in period 15, the worker will be willing to provide $\widetilde{e}$ in period 14 . Note that it is the expected future rent which disciplines the worker in period 14 while the current rent that is paid in period 14 is completely irrelevant for the effort choice of a selfish worker. As long as the selfish worker believes that the provision of the desired effort level is rewarded with the continuation of the relation in $t=15$, he will provide $e=\widetilde{e}$ in period 14, irrespective of the current rent in period 14 . This raises the question why the firm does not pay a very low or no rent in period 14 but "promises" to pay a substantial rent in period 15. Yet, if the worker believes that a low rent in period 14 is a signal that the relation will be terminated at the end of the period the current rent in period 14 will also affect the incentives for the worker in period 14. A low current rent in period 14 is then essentially a signal that there will be no future rent and thus the selfish worker has no longer an incentive to perform in period $14 .^{16}$

\footnotetext{
${ }^{14}$ We use the Fehr-Schmidt model because it is easy to apply in our context and captures some aspects of reciprocal behavior in a simple way. We do not regard our experiments as the appropriate environment for testing different fairness models. Other fairness models probably generate very similar equilibrium behaviors in our context.

${ }^{15}$ The fair workers need not be disciplined because they are willing to provide high effort levels in period $t$ as long as they receive sufficiently generous offers in period $t$.

${ }^{16}$ Our argument here is essentially an application of an argument in MacLeod and Malcomson (1998) to the context of a finitely repeated game. A crucial point in MacLeod and Malcomson (1998) is that firms cannot extract the future rents of the workers up-front by paying low wages or by charging entrance fees in the current period if this
} 
In a world in which fairness is a prominent concern, the belief that a low current rent signals the absence of future rents seems quite natural. A low wage may be taken as an indication that the firm is not much concerned about fairness and why should an unfair firm not also break her promise and change the trading partner in the next period? Whatever the source of the worker's belief is, as long as a low rent is believed to signal the termination of the relation at the end of the current period, the firm has an incentive to pay a high rent in the current period because this induces the selfish worker to perform in the current period. Yet, if the selfish worker also receives a current rent in $t=14$ the total expected income loss from the termination of the relation at the end of period 13 is even higher because the fired worker may lose rents for two periods. Thus, in period 13 and all the previous periods, even higher effort levels are enforceable by the threat of terminating the relationship.

The above argument rests on the possibility that firms and workers can form long-term relations. By design the ICR rules out that firms can ensure the reemployment of previous workers. Therefore, in the ICR selfish workers cannot be disciplined and, as a consequence, the average effort will be lower. The above argument also provides an equilibrium account for why firms may want to rely on private offers in the ICF. Since a long-term relation cannot be established through public offers, because every worker can accept a public offer, firms who want to maintain a long-term relation will rely on private offers. ${ }^{17}$

What is the potential impact of fair types in the C-condition? Since in the C-condition the contract enforcement problem is absent there is no need for the firms to discipline the workers and, hence, there is no need for the firms to offer rents to induce non-minimal effort choices. As a consequence, there is also no reason to enter into long-term relations and to rely on private offers. In fact, the existence of fair players may even provide a reason for the firms to rely primarily on public offers. This is so because a fair player is willing to reject offers that are perceived as unfair if the rejection decreases the firm's payoff with a sufficiently high probability. In contrast, a selfish player will accept any offer that gives him a positive material payoff. In case that the firms believe that there is a fraction of fair workers, and in case that the types of the workers have not yet been revealed, the firms have an incentive to make public

induces a belief that there will also be low wages (i.e., no rents) in the future. Given this belief, workers reduce their effort in the current period if they receive low wages in the current period. Note that in our context the belief is slightly different. If the workers do not receive a rent in the current period this is taken as a signal that the relation will be terminated at the end of the period.

${ }^{17}$ Our rationale for long-term relations in the ICF is certainly not the only possible one. For example, it is well known, that reputation building may occur even in situations where there are in fact no fair players but some players believe that there are fair players (see, e.g., Kreps et al. 1982). It may then be profitable for selfish players to behave as if they had a preference for fairness. Thus, it may be possible to construct somewhat similar equilibria as the one we have constructed even if there is only a very small number of fair subjects. 
offers because by making a public offer they can ensure that the selfish players can also accept their offers. Public offers are thus likely to increase the probability that low offers are accepted.

Our discussion has shown that in the presence of fair types long-term relations may be part of an equilibrium even in finitely repeated games like the ICF. However, it is well known that in repeated games there is typically a large number of equilibria and our ICF-condition is no exemption. Thus, it could be that the actual behavior of the subjects in our experiment deviates from the one outlined above simply because subjects play a different equilibrium. ${ }^{18}$ The plethora of equilibria in repeated games makes it all the more necessary to study the actual behavior of subjects in repeated settings. However, despite the limited predictive power of repeated game models they are in our view very useful for heuristic purposes because the behavioral patterns that prevail in particular equilibria suggests particular testable hypotheses. For instance, the equilibrium we described for the ICF suggests to test the hypotheses that private offers and long run relations will be more frequent in the ICF compared to the $\mathrm{C}$-condition, that effort enforcement in the ICF is based on the threat of terminating the relation in case of malfeasance, that effort in the ICF is higher than in the ICR, that current rents are shared in the ICF but not in the C-condition, etc. Thus, although the non-uniqueness of the equilibrium renders precise quantitative predictions impossible, focusing on particular equilibria provides fruitful qualitative hypotheses.

\section{Results}

Since there were seven firms, ten workers and 15 periods in each session the total number of potential trades is 105 . In the five ICF-sessions we observed in total 523 trades, in the five Csessions there were 519 trades and in the four ICR sessions we had 417 trades. This indicates that the potential number of trades was (almost) completely exhausted in all sessions.

\subsection{The Nature of Market Interactions}

Our first result concerns the nature of the bidding process in those two conditions where longterm relations were possible. The question is whether contractual incompleteness induces a different pattern of private versus public offers compared to the C-condition. The evidence on this question can be summarized in

\footnotetext{
${ }^{18}$ There is, of course, also the possibility that subjects do not play any equilibrium.
} 
Result 1: In the ICF-condition the large majority of trades is initiated by private offers while in the $C$-condition public offers initiate the large majority of the trades.

Figure 1 provides support for R1. It depicts the evolution of the relative share of trades in both the ICF- and the C-condition that are initiated by private offers. The figure shows that throughout all the periods the relative share of privately initiated trades is substantially larger in the ICF-condition. In the first two periods the difference across conditions is roughly 10 percentage points. After period two, the difference becomes much larger and in the final five periods it varies between 60 and 70 percentage points. This change over time is mainly due to the strong increase in the relative share of privately initiated trades in the ICF-condition. After period seven this share is almost always above 80 percent and reaches even 90 percent. Thus Figure 1 unambiguously shows that private offers are the preferred choice in the ICF-condition while public offers are the preferred choice in the $\mathrm{C}$-condition.

FIGURE 1: Relative share of trades initiated by private offers under complete and incomplete contracts

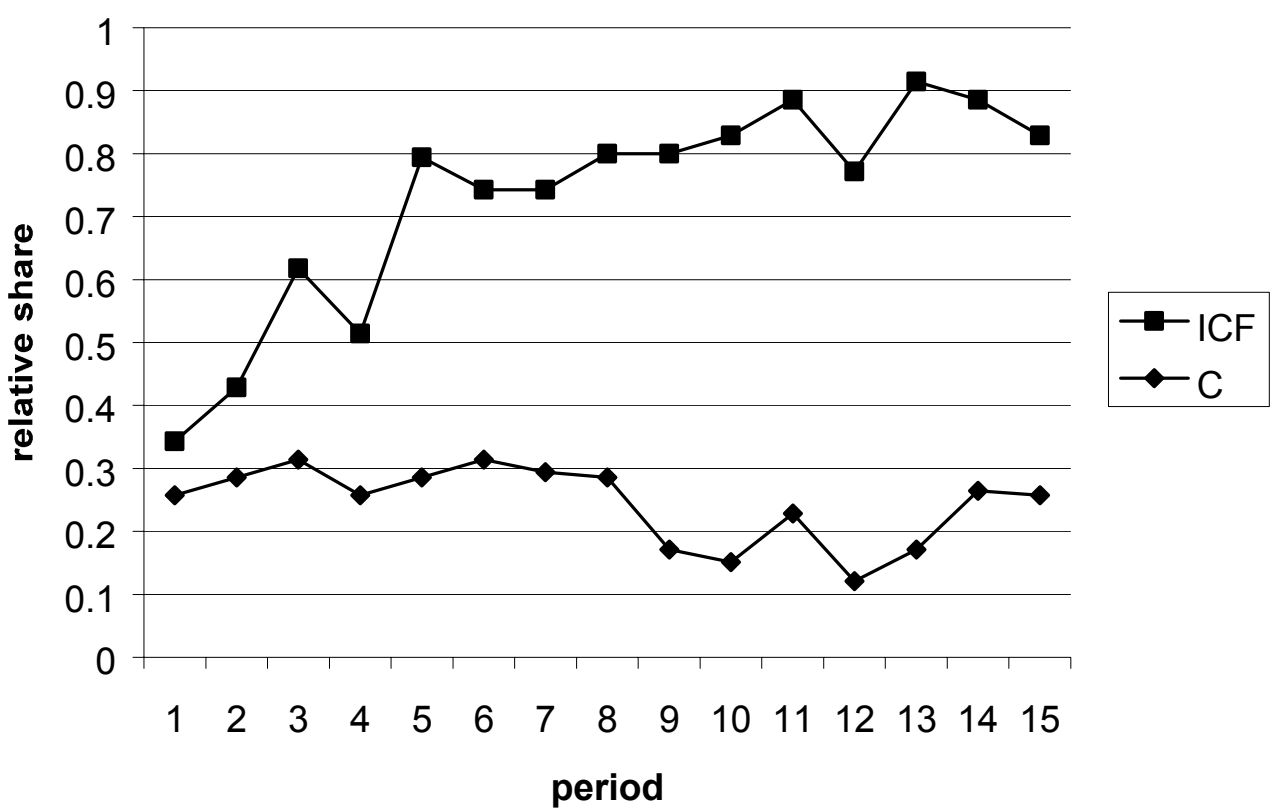

Figure 1 shows the aggregate picture if we average over all five ICF- and C-sessions. Despite some variability within the ICF- and the $\mathrm{C}$-sessions similar results also hold for the individual sessions. To show this similarity we have computed the relative share of trades that are initiated by private offers for each session. Across the ICF-sessions the relative share of private offers 
varies between 61 and 90 percent while in the C-sessions it varies between 9 and 43 percent. A non-parametric Mann Whitney test, with the relative shares in each session as the observations, indicates that this difference is significant at the 1 percent level $(p=0.009)$.

R1 suggests that in the C-condition firms do not care much about the identity of their trading partner since they predominantly make public offers. They just seem to be interested in finding a trading partner regardless of the partner's identity. In the ICF-condition, however, the worker's identity seems to matter a lot because in most cases firms make private offers. Our next result provides evidence in favor of this interpretation.

Result 2: Firms addressed the majority of private offers to their previous employees. The probability of making a private offer to the previous employee is higher the higher the employee's effort in the previous period, the lower the negative surprise relative to the firm's expected effort level and the higher the positive surprise relative to the firm's expected effort level.

Support for R2 comes from Tables 2 and 3 and Figure 2. Table 2 displays the evolution of the frequency of private offers to the previous trading partner relative to all the private offers. It indicates that the clear majority of private offers goes to the previous worker. After period five between 60 and 79 percent of all the private offers go to the previous workers. This can be taken as a first indication that the firms are interested in forming long-term relations with particular workers.

TABLE 2: Evolution of private offers to the previous employee relative to all the private offers

\begin{tabular}{ccccccccccccccc}
\hline \hline Period & 2 & 3 & 4 & 5 & 6 & 7 & 8 & 9 & 10 & 11 & 12 & 13 & 14 & 15 \\
Percent & 41.7 & 40.0 & 52.6 & 48.5 & 66.7 & 72.0 & 60.0 & 72.0 & 60.0 & 71.4 & 78.6 & 75.9 & 61.1 & 69.2
\end{tabular}

Firms' interest in forming a long-term relation with a worker depends crucially on the worker's performance. R2 means that firms condition contract renewal on the worker's effort choice. Figure 2 reveals that there is indeed a very strong positive relation between the probability that the previous worker receives a private offer and his effort choice. For effort levels below seven this probability is roughly 0.2 or less while for $e \geq 7$ it is substantially above 0.5 . If the worker provided the maximum effort in $t-1$ the probability of getting a new offer in $t$ is close to 1 . 
FIGURE 2: Probability of a private offer to the previous worker as a function of the worker's effort (ICF-treatment)

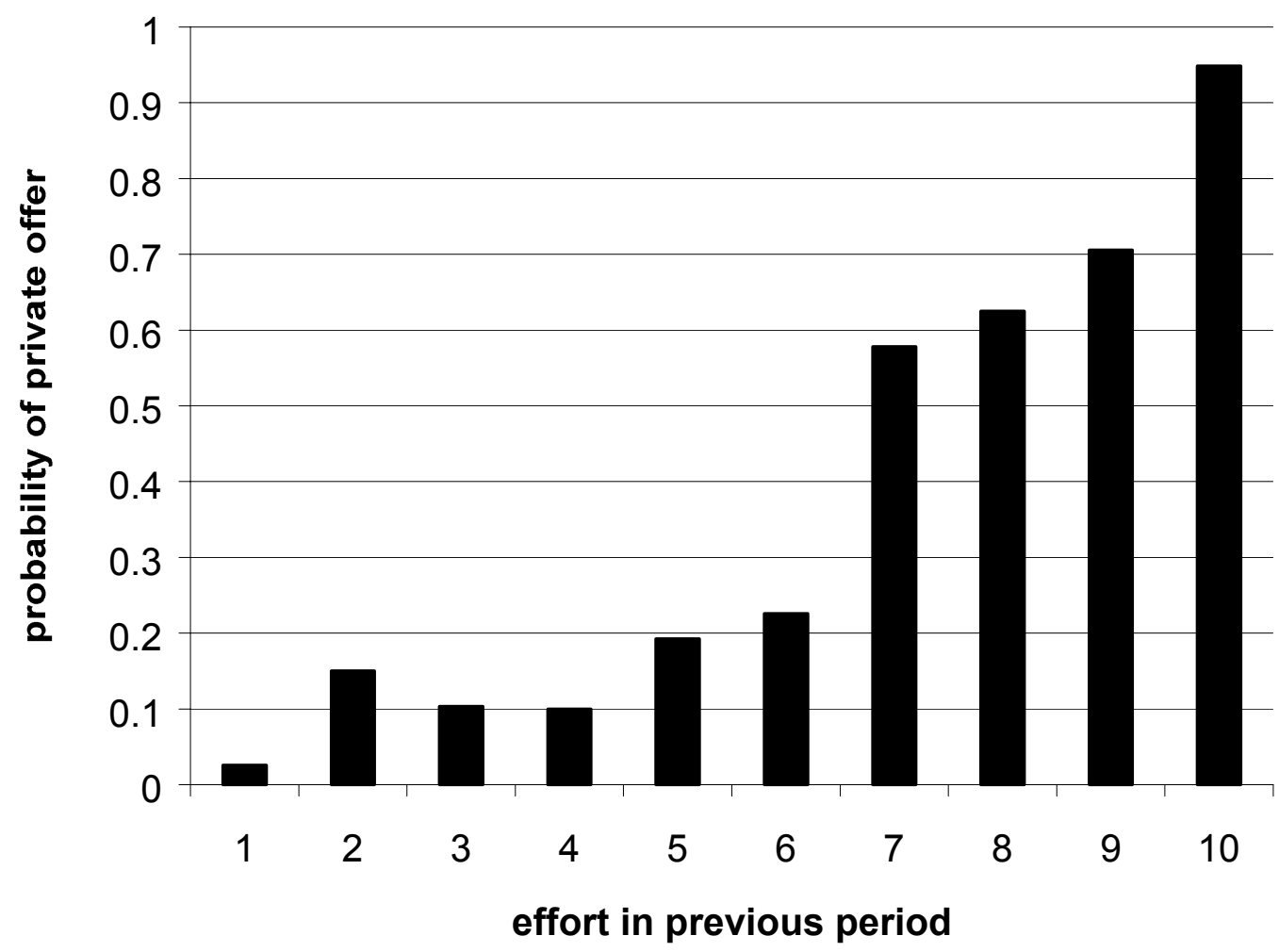

Figure 2 strongly suggests that the firms adopted a policy of contingent contract renewal: High and satisfactory performance was rewarded with a new private offer while in case of low and unsatisfactory performance the probability of "firing" was quite high. Further evidence for this interpretation is given in Table 3. The table presents the results of a probit-regression that regresses the probability of a private offer to the previous worker on the worker's previous effort, on positive and negative surprise, on the previous length of the relationship controlling for session fixed effects. In the table we show the robust standard errors for each coefficient estimate. These standard errors provide very conservative significance tests because they are based on the assumption that only the observations across the five ICF-sessions are statistically independent while for the observations within each session no independence is assumed. Table 3 shows a strong and significant positive impact of the previous effort. In addition, if the worker provided effort in excess of what the firm expected (positive surprise) the probability increases significantly while if the firm's expectation was disappointed (negative surprise) the probability decreases. Interestingly, the previous length of the firm-worker relation is also highly significant. This provides a first indication that long-term relations give rise to relation-specific reputational 
capital making firms reluctant to fire workers with whom they have interacted more often in the past. We will take up this issue in more detail in $\mathrm{R} 8$ below.

TABLE 3: Probability of making a private offer to the previous worker in the ICF-treatment

\begin{tabular}{lc}
\hline \hline Effort in previous period & $.125^{* *}(.052)$ \\
Positive surprise & $.192^{* *}(.077)$ \\
Negative surprise & $-.836^{* *}(.381)$ \\
Previous length & $2.449 * * *(.653)$ \\
constant & $-5.045^{* * *}(1.535)$ \\
\hline & $\mathrm{N}=488$ \\
& $\mathrm{LL}=-41.93$ \\
& Wald $(3)=11.89$ \\
& Prob $=.000$ \\
& Pseudo $\mathrm{R}^{2}=.8747$
\end{tabular}

Note: The estimation procedure is a probit regression with robust standard errors (in parentheses). The regression includes dummies to control for session effects. $* * *$ indicates significance at the 1-percent level, $* *$ at the 5-percent level and $*$ at the 10 -percent level, respectively.

We also ran separate probit regressions for the individual sessions. Yet, the general pattern is the same across sessions. ${ }^{19}$ Thus, taken together these results suggest that the firms followed a contingent renewal policy but in case of a long lasting relation the probability of firing for malfeasance was generally lower.

R2 strongly suggests that in the ICF-condition the firms were interested in keeping the same worker if the worker provided high effort levels that met the firms' expectations. The next question then is whether the firms were successful in establishing long-term relations. Our next result provides an answer.

Result 3: In the C-condition the vast majority of trades takes place in one-shot transactions while in the ICF-condition the majority of trades takes place in long lasting relations.

Support for R3 is given in Figure 3. The figure presents the cumulative frequency of trades in firm-worker relations of different length in the C- and the ICF-condition. As one can see, more than 70 percent of all the trades in the C-condition took place in one-shot encounters and 90

\footnotetext{
${ }^{19}$ We also experimented with "shirking", i.e., $e<\widetilde{e}$ and excess effort $(e \geq \widetilde{e})$ as regressors. It turns out, however, that when previous effort is included, shirking and excess effort are sometimes bad explanatory variables while positive and negative surprise are always significant and have the expected sign.
} 
percent of the trades took place in interactions that lasted one or two periods. This differs sharply from the ICF condition in which only one third of the trades took place in one-shot encounters and roughly 50 percent of the trades took place in relations that lasted for four or more consecutive periods. Moreover, roughly 40 percent of the trades in the ICF took place in relations that lasted 8 or more periods.

FIGURE 3: Cumulative frequency of trades in relationships of different lengths in the $\mathrm{C}$ - and the ICF-treatment

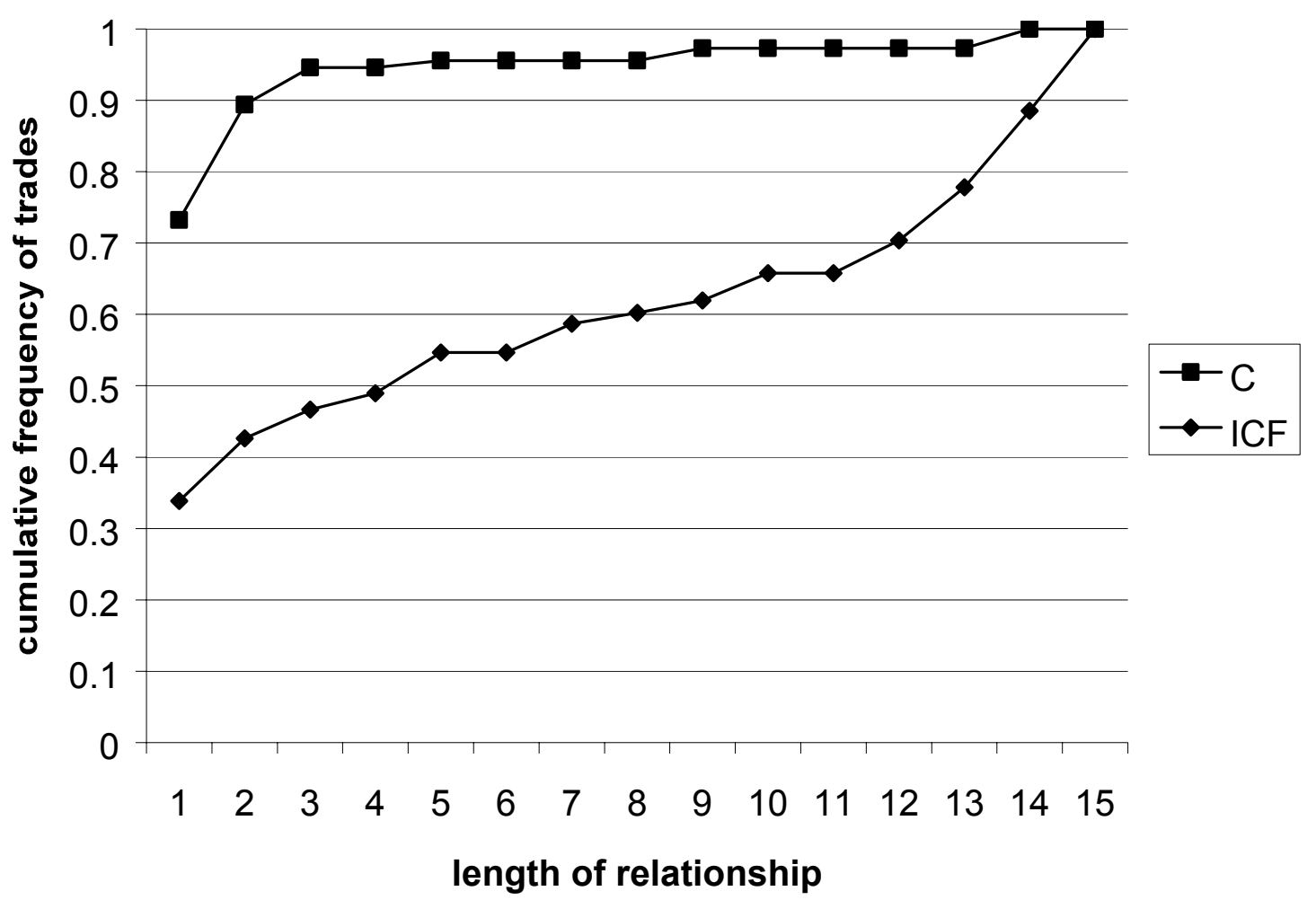

A similar picture emerges at the session level. To show this result we computed for each trade how long the trading parties had stayed together previous to the respective trade. Then we took the average "length of the relation previous to the trade" for each session. It turns out that in all five C-sessions this measure is lower than in each of the five ICF-sessions. Thus, the difference across treatments is significant ( $p=0.009$, Mann Whitney test).

Most one-shot encounters in the ICF-condition took place in early periods. In period two and period three the separation rate, i.e., the rate at which the traders change their trading partners is slightly more than 60 percent. The separation rate sharply declines after period three (eventually reaching a level of about 20 percent). This suggests that at the beginning there was a 
search phase during which the traders attempted to find a good match, and once they had found one they tended to continue the relation.

Result 4: In the ICF-condition there is little disagreement about contract terms while in the Ccondition many offers are not accepted by the workers.

Support for R4 comes from Figure 4, which shows the average number of offers per session that are in excess of the number of trades. The figure illustrates that - except for the first five periods - there are typically only one or two excess offers in an ICF-session. Thus, after period five of an ICF-session there were typically only 8 or 9 offers per period and seven of them were accepted. The small number of excess offers in the ICF indicates that most offers led directly to a trade so that little disagreement about contract conditions occurred.

FIGURE 4: Evolution of the number of excess offers per session in the C-and the ICF-treatment

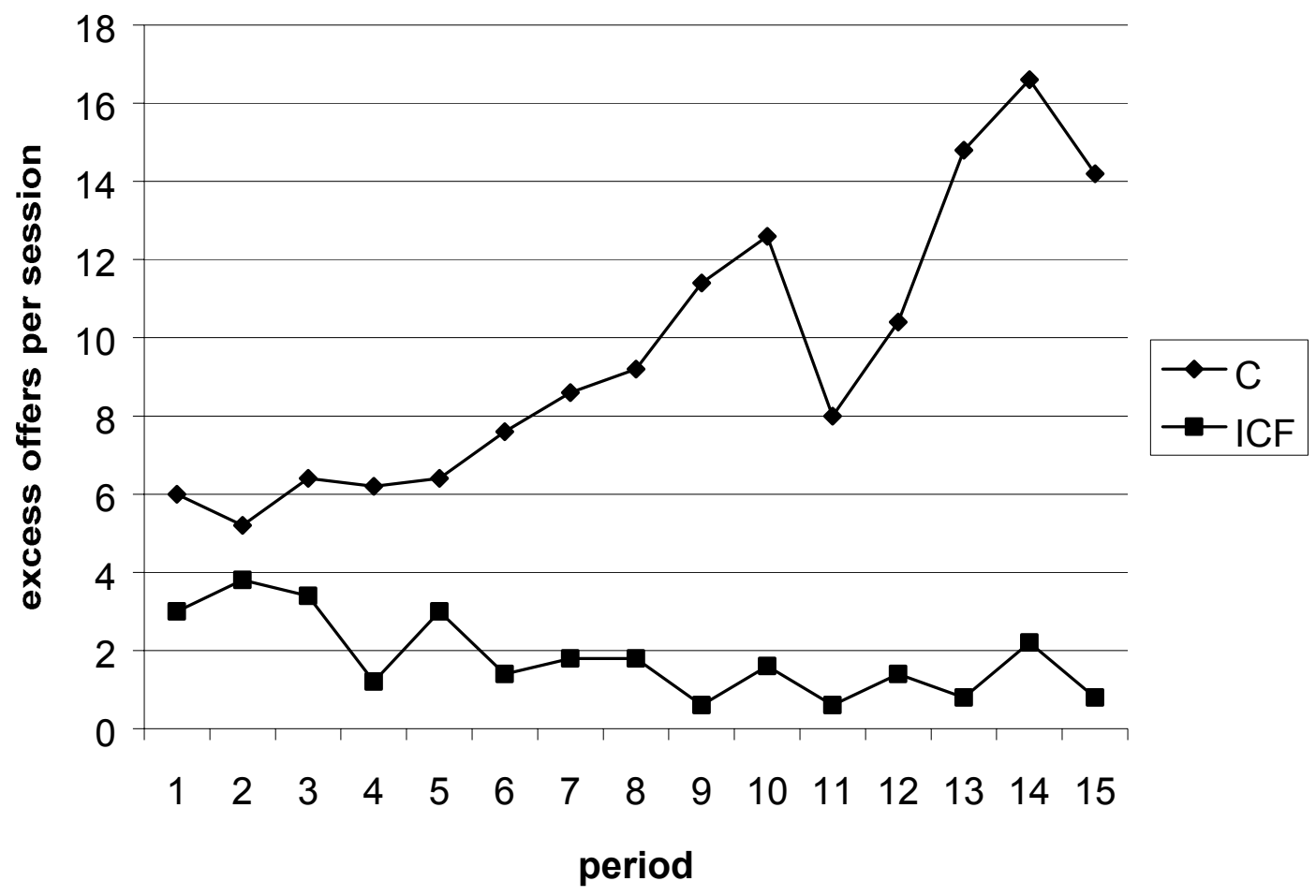

In the C-condition the picture is quite different. The number of excess offers per period is rarely below six and after period 5 there is a strong increase in the number of excess offers per period reaching 14 excess offers in the final period. Thus, in the $\mathrm{C}$-condition there occurs much more disagreement about contract terms. Firms predominantly made public offers and the 
workers did not accept many of these offers. As a consequence, firms gradually had to improve their offers until workers accepted them.

The temporal pattern of acceptance within a period was also a very different across conditions. In the ICF-condition most offers were immediately accepted so that the trading periods quickly ended. In contrast, in the C-condition the time limit for the trading period was virtually always exhausted. By not accepting the prevailing offers the workers put pressure on the firms to improve their offers because - due to the time limit - firms were afraid that they might not be able to trade.

The aggregate results illustrated in Figure 4 are quite representative for the individual sessions. In the C-sessions the number of excess offers per session varies between 85 and 204 while in the ICF-sessions we observed only between 16 and 38 excess offers per session. Therefore, this difference across conditions is significant $(\mathrm{p}=0.009$, Mann Whitney test).

Taken together the first four results show that contractual incompleteness causes markets to function very differently compared to the complete contract condition. If effort enforcement is no problem most transactions are one-shot and the firms do not care about the identity of the trading partner. In addition there is a lot of disagreement about contract conditions as indicated by the number of excess offers. If third parties cannot enforce the effort, the firms care a lot about the identity of the trading partners. Firms establish long-term relations with reliable workers by implementing a policy of contingent contract renewal. After an initial phase during which firms search for reliable workers, one-shot encounters are relatively infrequent and little disagreement about contract conditions occurs. In most cases the firms make just one offer to one of the workers and this offer is accepted. Moreover, the evidence indicates that long-term relations make firms, ceteris paribus, more reluctant to fire workers suggesting the existence of relation-specific reputational capital. All these differences in market interactions across conditions can be attributed to contractual incompleteness. However, we do not yet know the precise reasons and consequences of the firms' contingent renewal policy and the resulting longterm relations in the ICF.

\subsection{Reasons and Consequences of Contingent Contract Renewals and Long-Term Relations}

Why did the firms predominantly rely on private offers in the ICF-condition while in the Ccondition public offers prevailed? In view of the large differences across conditions one would conjecture that the relative profitability of private offers differs across conditions. Our next result shows that this in fact holds. 
Result 5: Except for the final period, private offers are much more profitable than public offers for the firms in the ICF-condition. In contrast, in the C-condition private offers are less profitable for the firms than public offers. Irrespective of the type of the offer, firms make higher profits in the C-condition compared to the ICF-condition.

R5 is supported by Figure 5, which presents the evolution of the firms' average profits in trades initiated by different types of offers across conditions. In the ICF the profit from a private offer varies between 26 and 40 in the first 14 periods while the profit from a public offer varies between 3 and 27. Only in the final period the profit from a private offer is comparably small. These profit differences are significant. If we regress the firms' profit per trade in the ICF on a constant and a dummy for "private offer" the coefficient for the dummy is 16.8 and significant at the 1 percent level. In contrast to the ICF, in the C-sessions private offers are less profitable. If we perform the same regression for the $\mathrm{C}$-condition, the results indicate a significant $(\mathrm{p}<0.08)$ and negative impact of the private offer dummy. ${ }^{20}$ Thus it was indeed more profitable to make private offers in the ICF while in the C-condition public offers were more profitable.

In the $\mathrm{C}$-condition profits steadily rise over time. Towards the end the profit from a public offer stabilizes around $\pi_{f}=70$. Note that the gains from trade, which are given by $10 e-c(e)-5$, can be at most $10 \cdot 10-18-5=77$. If a firm earns $\pi_{f}=70$ the workers' share of the gains from trade can be at most equal to 7 . This indicates that the distribution of the gains from trade was quite uneven in the $\mathrm{C}$-condition. The uneven payoff distribution provides a reason for why there were so many offers in excess of the number of trades in the C-condition. Over time the firms in the C-condition made worse offers which the workers frequently hesitated to accept (see Figure 4). Nevertheless the increasing profits per trade over time indicate that the firms were ultimately successful in enforcing low gains from trade for the workers.

\footnotetext{
${ }^{20}$ All significance tests are based on robust standard errors that assume that observations across sessions, but not within sessions, are independent.
} 
FIGURE 5: Firms' average profits in trades initiated by private or public offers in the C-and the ICF-treatment

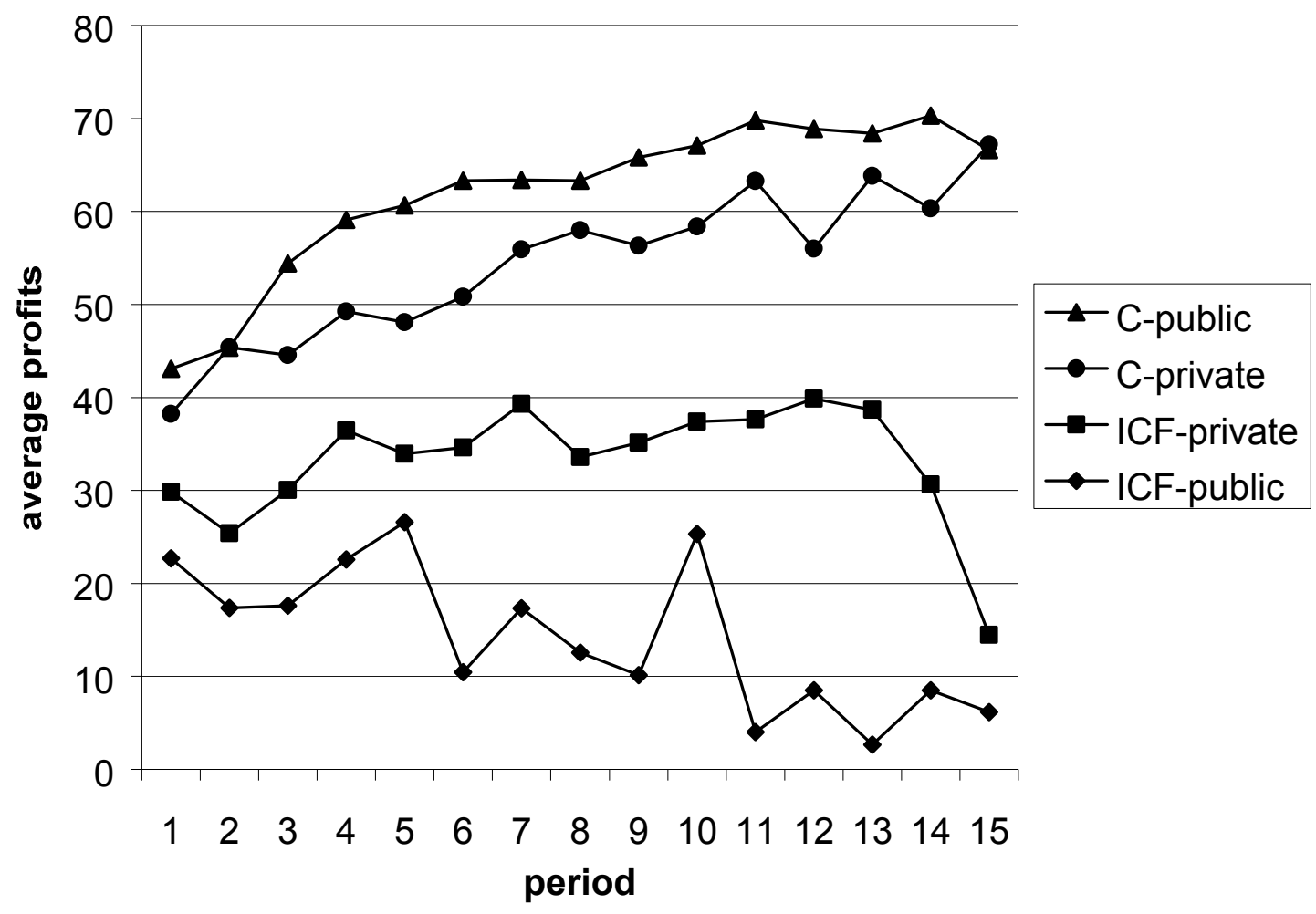

There are in our view two potential reasons why the firms implemented a contingent renewal policy. One reason is purely psychological and has to do with fairness concerns. If, in response to a generous offer with a high effort demand, a worker shirks it seems quite natural that the firm feels cheated. Reciprocal fairness then dictates to punish the worker by not renewing his contract. The other reason for a contingent renewal policy is economic because by making the renewal of the contract contingent on the worker's satisfactory performance the firm may create a material incentive for contract enforcement. This material incentive exists, however, only if the denial of contract renewal imposes a loss on the workers. It is, therefore, important to examine whether those workers who did not get their contract renewed faced a loss.

Result 6: In all periods the denial of contract renewal imposed costs on the workers.

To examine this question we have computed for every period $t$ a proxy for the total rents of the trading workers. For this purpose we computed the average of all present and future incomes of those workers who traded in period $t$. The average income of a worker, who trades in $t$, over all periods from $t$ to $T=15$ measures the average value of a job in $t$. We denote this value by $V_{t}^{e}(e$ 
stands for "employed"). In addition, we computed the average value of being without a job in period $t$ which we denote by $V_{t}^{u}$ ( $u$ stands for "unemployed"). $V_{t}^{u}$ is given by the average income of a worker, who is unemployed in period $t$, from period $t$ to $T=15$. The difference $V_{t}^{e}-V_{t}^{u}$ represents a proxy for the total rent of a worker who is employed in $t$. Table 4 shows the evolution of $V_{t}^{e}-V_{t}^{u}$ over time. It turns out that this expression is positive in all 15 periods.

TABLE 4: Total rents of trading workers

\begin{tabular}{cccccccccccccccc} 
Period & 1 & 2 & 3 & 4 & 5 & 6 & 7 & 8 & 9 & 10 & 11 & 12 & 13 & 14 & 15 \\
\hline \hline $\boldsymbol{V}_{\boldsymbol{t}}^{\boldsymbol{e}}-\boldsymbol{V}_{\boldsymbol{t}}^{\boldsymbol{u}}$ & 102 & 50 & 66 & 113 & 148 & 105 & 139 & 110 & 99 & 95 & 91 & 79 & 71 & 42 & 27
\end{tabular}

This implies that, in any period $t$, the denial of contract renewal imposed a cost on the worker. To see this assume that a worker, who does not get an offer in period $t$ from his previous firm, finds another trading partner in period $t$ with probability $\mu<1 .^{21}$ The worker's expected future income is thus $\mu V_{t}^{e}+(1-\mu) V_{t}^{u}$. If, instead, the worker can trade for sure in period $t$ with his previous firm his expected future income is $V_{t}^{e}$. Therefore, by not renewing the contract, the firm can impose an expected loss of $(1-\mu)\left(V_{t}^{e}-V_{t}^{u}\right)$ on the worker. Note also that the probability of not getting a new trading partner, $(1-\mu)$, is the higher the larger the number of bilateral long-term relations in the market. R6 also means that employed workers were on the average always better off than unemployed workers. Unemployment was thus involuntary in the sense that unemployed workers would have strictly preferred a job at the prevailing wages.

Irrespective of the reason for the contingent renewal policy of the firms in the ICFcondition R6 implies that this policy created material incentives for the workers to provide nonminimal effort levels. It is, therefore, interesting to examine to what extent the material incentives that are present in the ICF contributed to the provision of high effort levels. We can examine this by comparing the effort levels between the ICF- and the ICR-condition because in the ICR no such material incentives were present.

Result 7: The effort level in the ICF-condition is much higher compared to the ICR-condition. The effort level is highest in the C-condition.

\footnotetext{
${ }^{21}$ Let $n_{t}$ denote the number of workers who trade with the previous firm in period $t .10-n_{t}$ denotes the workers who are in the market and search for a job in period $t$ and $7-n_{t}$ is the number of firms who do not trade with their previous worker and search for another worker in $t$. Then a worker who is denied contract renewal in period $t$ has probability $\mu_{t}=\left(6-n_{t}\right) /\left(9-n_{t}\right)<1$ of trading with another firm.
} 
Evidence for R7 is given in Figure 6, which presents the evolution of average effort in all three conditions. There are several remarkable features in this figure. First, in all the periods there is a clear order. Effort is highest in the C-condition, second highest in the ICF-condition and lowest in the ICR-condition. We find it particularly remarkable that the possibility of forming long-term relations and of implementing a policy of contingent renewal in the ICF-condition leads to a higher effort compared to the ICR-condition already in period one. Second, over time there is a substantial increase in the average effort level in the ICF-condition. Third, in the final period there is a substantial drop in the average effort level in the ICF-condition. This is consistent with the view that the selfish workers can be disciplined by the threat of firing only during the prefinal periods.

FIGURE 6: Evolution of average effort over time

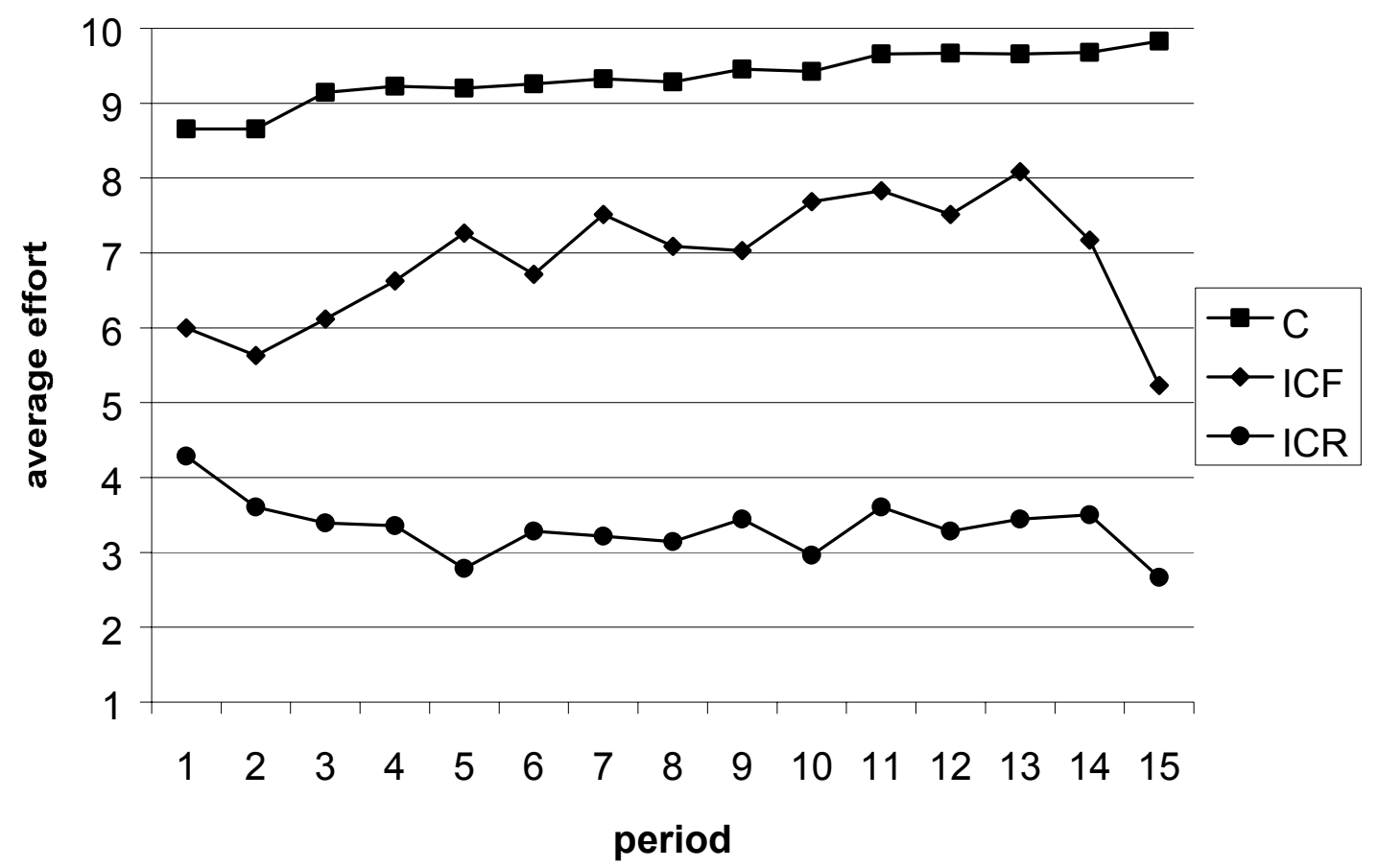

Figure 6 suggests that when there is an excess supply of workers, contingent renewal policies are a very effective device for the elicitation of high effort levels. While in the ICRcondition the average effort was rarely above $e=4$, firms in the ICF could enforce between $e=7$ and $e=8$ most of the time. These differences also emerge at the level of individual trades (see Figure 7). In the ICR-condition the maximum effort was rarely achieved and the most frequent effort level was $e=1$. In 43 percent of all the trades the workers chose the minimal effort in the ICR-condition and in 36 percent of the trades the workers provided between $e=4$ and $e=7$. In less than 6 percent of the trades $e \geq 8$ is achieved in the ICR-condition. The ICF-condition 
sharply differs from this because in 36 percent of the trades the maximum effort is achieved and in another 29 percent of the trades $e$ is between 7 and 9 . The maximum effort is the mode in this condition. These effort differences across conditions are statistically significant $(p=0.028$, Mann Whitney test with the average effort per session as the unit of analysis).

FIGURE 7: Distribution of effort in the ICF- and the ICR-condition

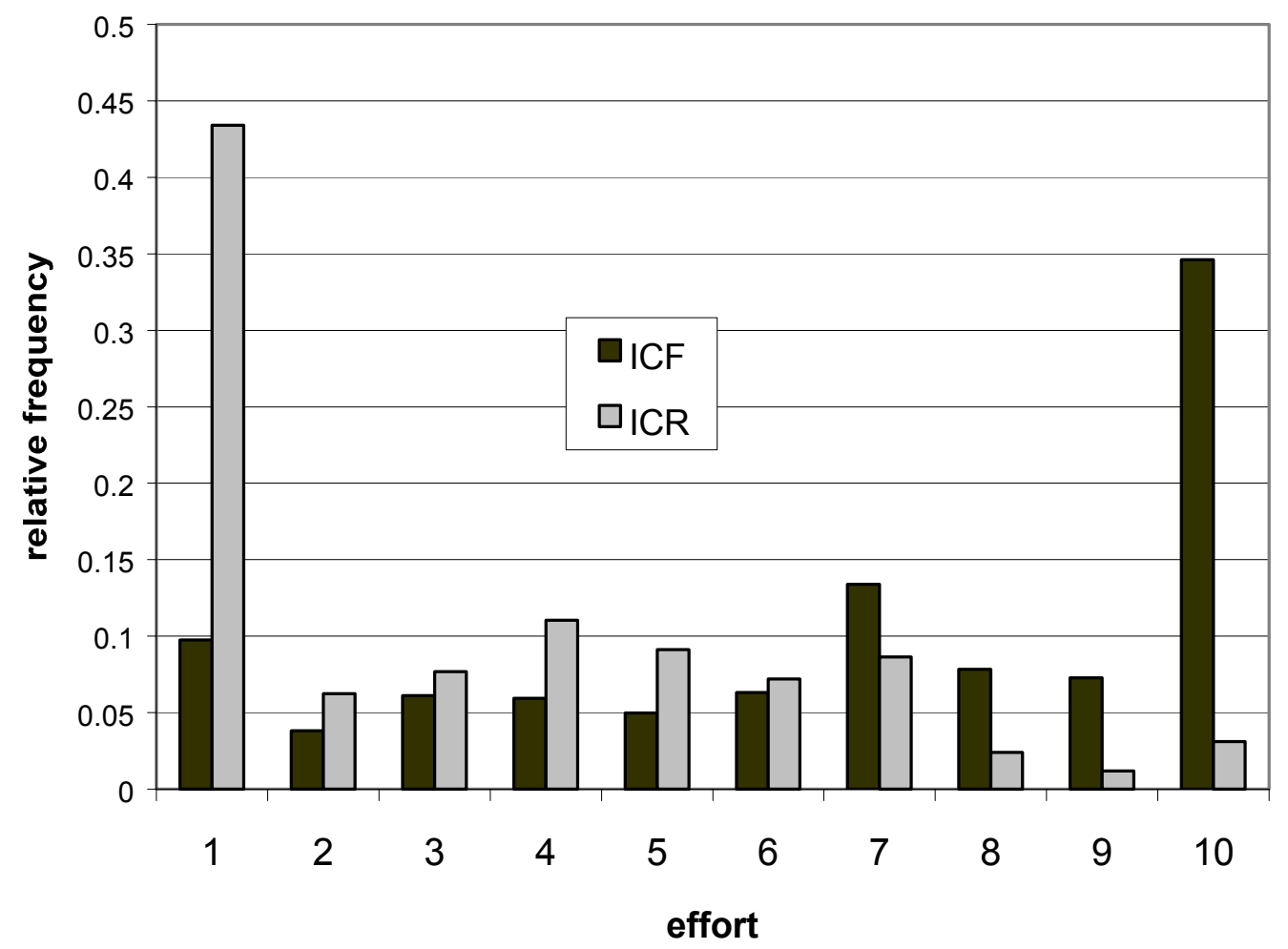

From Table 3 we know that the previous length of the relation had a large and highly significant positive impact on the probability of making an offer to the previous worker. Thus, for the same past effort level and the same level of positive or negative surprise a worker who has been together with a firm for more periods was more likely to be reemployed by the firm. In economic terms this makes only sense if firms value longer lasting relationships more highly. Recall that in the presence of a policy of contingent renewal - workers in longer lasting relations performed on the average better in the past. Thus these workers actually exhibited a higher degree of trustworthiness. In our view there are at least two reasons why a firm may infer from past trustworthy behavior that a worker will also exhibit trustworthy behavior in the present period. First, past trustworthy behavior may be taken as an indication that the worker has fairness preferences that favor cooperation - the worker is seen as intrinsically more trustworthy. Second, 
past trustworthy behavior may be seen as an indication that the firm and the worker have arrived at a viable implicit agreement based on repeated interaction incentives. Note that in our context the establishment of an implicit agreement is far from obvious - necessitating a lot of trust and belief coordination that cannot be taken for granted. For example, if a firm offers a generous wage in combination with a high desired effort level, the firm may end up with a high loss if the worker shirks. Likewise, a worker who performs well because he hopes to be reemployed may regret this choice if he is in fact not reemployed next period. Thus, the mutual trust that helps to establish implicit agreements may be viewed as a relation-specific asset that renders firms reluctant to fire their workers.

If it is indeed the case that longer lasting relations increased the firms' trust into their worker we should observe that, on the average, firms in longer lasting relations expect higher effort levels and experience less uncertainty with regard to the effort level. Recall that in each period firms indicated their expected effort level and the uncertainty of their expectation, which enables us to examine these questions.

Result 8: In the ICF-condition, during the initial periods of a long run relation firms' expected effort and the actual effort are strongly increasing in the length of the relationship while firms' subjective uncertainty about the effort is strongly decreasing. With an increasing length of the relation the increase in expected and actual effort and the decrease in subjective uncertainty become weaker.

We provide support for R8 by means of Figure 8 . The figure plots expected effort, actual effort and subjective uncertainty about the effort as a function of the previous duration of the trading relation. $^{22}$ The figure illustrates that firms expected a strong rise in effort between period 1 and period 4 of a relationship. Between period 5 and 8 the increase is less strong. Moreover, the actual effort level shows an equally remarkable time pattern. It roughly matches the expected effort level indicating that the value of a relationship indeed increases with the length of the relation. This pattern of the actual effort level provides a rationale for the increase in actual effort over time in the ICF - as illustrated in Figure 6. In the course of the ICF-sessions long-term relations became more frequent which led to the observed increase in effort over time. Further evidence for an increase in the value of a relationship over time is provided by the strong decrease in the subjective uncertainty with respect to the expected the effort level (see Figure 8).

\footnotetext{
${ }^{22}$ Note that when firms indicate the expected effort and their subjective certainty they are (in the current period) already matched again with a worker. Therefore, in Figure 8 the variable "previous length of the relation" also includes the current period. R8 also holds, however, if we exclude the current period.
} 
Recall that firms indicated complete uncertainty by the number 1 and complete certainty by the number 7. For relationships that last between 4 and 14 periods the average uncertainty of firms is always between 6 and 7 which suggest a very high amount of trust.

Another interesting feature of Figure 8 is the reduction in expected and actual effort and the increase in subjective uncertainty towards the end of the experiment. Note that very long relations are more likely to include the final period. In the final period many firms expected a significant decrease in effort levels and an increase in subjective uncertainty, and the actual effort levels did indeed decrease in the final period (see Figure 6). This is an indication that a non-trivial part of the trust that was exhibited in the non-final periods of the relations was built on incentives arising from repeated interactions. However, as we will see in our discussion of R9 and R10 below there is also evidence that intrinsic trustworthiness in the form of fairness preferences has played a role.

FIGURE 8: The average values of expected effort, actual effort and subjective uncertainty about effort as a function of the previous length of the relation (ICF-treatment)

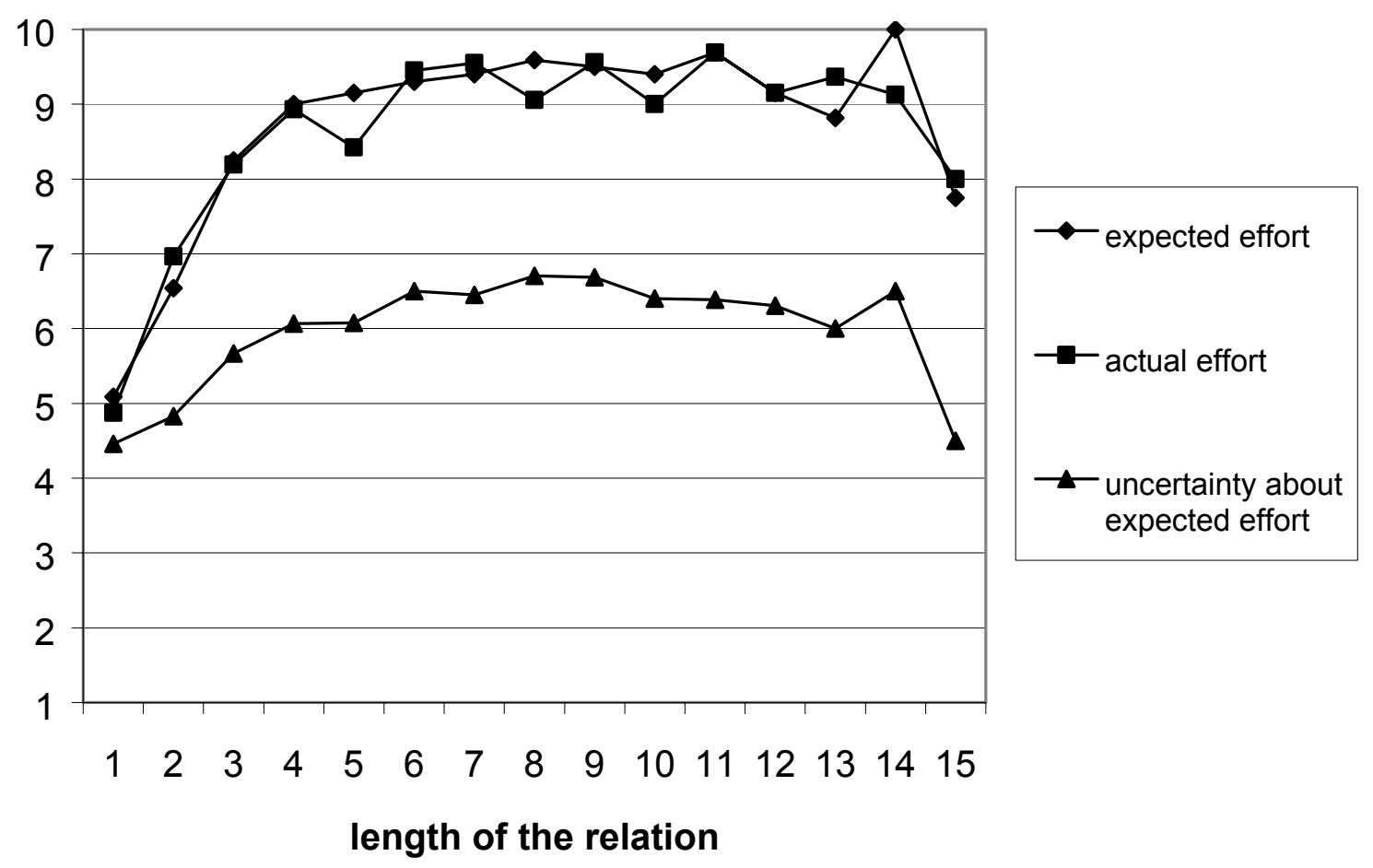

R8 suggests that - apart from the reduced trust taking place in the final period of the experiment - long-term relations were characterized by a higher degree of trust and trustworthiness than short-term relations. This provides a reason for an important part of R3, i.e., for the firms' 
reluctance to fire workers with whom they had interacted more often in the past. Thus, this part of R3 in combination with R8 indicates that reputational assets were created in long-term relations, which contributed to the bilateralization of the market.

Our previous results show that the parties in the ICF had strong reasons to form long-term relations. Yet, how did they manage to establish the necessary trust? After all firms and workers who wanted to establish a long-term relation had to solve a complex problem. How could a firm signal to the worker that it was interested in maintaining the relationship in case of satisfactory performance? How could a worker signal that he was interested in getting an offer from the same firm again? For the worker the problem seems to be easier because by providing the maximum effort or by providing a higher effort than requested by the firm the worker could recommend himself to the firm. For the firm, however, the problem seems more difficult. One method could be a generous contract offer. By making a generous offer and demanding a high effort level the firm might be able to communicate the willingness to make a generous offer to the worker again in the next period provided the worker's performance is satisfactory. Recall that making a generous offer exposes the firm to a considerable risk because if the worker shirks the firm incurs a loss. But perhaps it is exactly this exposure to the risk of shirking that makes the firm's signal "psychologically credible". If a generous offer increases the credibility of a contingent renewal policy one would expect that, for a given desired effort level, there is a positive relation between the wage and the worker's effort. The reason is that, if the worker's belief in a policy of contingent renewal is fostered by a generous contract offer, the worker faces, subjectively, stronger material incentives to perform well. One would expect, however, also a positive correlation between wage and effort if there are fair types among the workers.

Another method to foster the worker's belief in a contingent renewal policy could be to initiate the trade by a private offer. From an economic viewpoint it seems at first sight irrelevant for the credibility of the policy whether trading is initiated via a private or a public offer. However, if private offers are interpreted as a signal that the firm is interested in a long-term relation the worker might be more willing to provide a high effort level. If this is the case we should observe that a private offer increases the worker's effort choice in the ICF. Alternatively, private offers may have a purely psychological effect on workers' effort choices that have nothing to do with the credibility of signaling a contingent renewal policy. The mere fact that in a situation of excess supply of workers a firm singles out a particular worker may render the worker grateful, which in turn may raise his effort. If this argument is empirically relevant we should observe that private offers raise effort in the ICF and in the ICR. To examine the above 
hypotheses about the various determinants of the workers' effort choices, we ran several regressions. The results of these regressions can be summarized as follows.

Result 9: Both in the ICF- and the ICR-condition the actual effort chosen by the worker is positively related to the wage and to the private offer dummy. The firm's desired effort has no effect on the actual effort. The previous length of the trading relation increases the effort in the ICF.

The regressions supporting R9 are presented in Table 5. Since the effort cannot be lower than 1, nor higher than 10 and since in the ICF (ICR) many effort choices are at the upper (lower) boundary we used a censored regression technique. In addition, we report robust standard errors that also allow for heteroskedasticity. Both in the regression for the ICF- and the ICR-condition we control for session effects by including session dummies and for period effects by including period dummies. The period dummies constitute suitable controls for the endgame effect observed in the ICF. In the regressions for the ICF- and the ICR-condition the coefficients on "wage" and "private offer" are positive and highly significant while "desired effort" is insignificant. The result for the ICF-regression is thus consistent with the hypothesis that in the ICF a higher wage and a private offer foster the credibility of the firm's contingent renewal policy. However, the fact that "wage" and "private offer" are also significantly positive in the ICR suggests that fairness concerns shape effort behavior, too.

In the regression for the ICF "previous length" is significantly positive indicating that workers' trustworthiness increases with the length of the relation. This increase in trustworthiness may be due to the fact that a worker's experience with a firm's contingent renewal policy enhances the credibility of the renewal policy thus providing better pecuniary incentives for the worker. The increase may, however, also be due to a loyalty effect. Perhaps the trust that arises from the repeated experience of being reemployed induces workers to become more loyal to their firms, i.e., they are more willing to take their firm's interests into account when choosing the effort level. If this conjecture is true then we should observe that - in the final period - workers who had been in a longer relation with their firms provide - ceteris paribus higher effort levels because in the final period pecuniary incentives are absent. To test this we ran the same regression as in Table 5 with the data from period 15 of the ICF. It turns out that even in period 15 the coefficient for "previous length" is positive and significant $(p=0.016)$ suggesting the existence of a loyalty effect. This loyalty effect may also explain why in the final 
period of the ICF average effort is considerably higher than in the final period of the ICR (see Figure 6).

TABLE 5: Determinants of effort in the conditions with incomplete contracts

\begin{tabular}{lcc}
\hline \hline & \multicolumn{2}{c}{ Dependent variable: effort } \\
\hline Wage & ICF-treatment & ICR-treatment \\
Desired effort & $.184^{* * *}(.011)$ & $.164 * * *(.014)$ \\
Private offer & $.049(.066)$ & $.065(.081)$ \\
Previous length & $.878^{* * *}(.284)$ & $.791^{* * *}(.294)$ \\
constant & $.176^{* * *}(.052)$ & - \\
& $-2.185^{* * *}(.499)$ & $-1.754^{* *}(.732)$ \\
& $\mathrm{N}=523$ & $\mathrm{~N}=417$ \\
& $\mathrm{LL}=-716.53$ & $\mathrm{LL}=-599.38$ \\
& Wald $\chi(22)=1015.14$ & Wald $\chi(20)=648.11$ \\
& Prob $=.000$ & Prob $=.000$ \\
\hline
\end{tabular}

Note: The estimation procedure is a censored regression with robust standard errors (in parentheses). The regressions include period dummies to control for time effects and session dummies to control for session effects. $* * *$ indicates significance on the 1-percent level, ** on the 5-percent level and * on the 10-percent level, respectively.

From a theoretical viewpoint (see Appendix 1) the effectiveness of a contingent renewal policy in the first 14 periods requires that there is a rent in the final period because in the absence of a rent rational and selfish workers cannot be disciplined in the pre-final periods. From Table 4 we know already that the workers earned a rent in the final period of the ICF. It would, however, be reassuring if the rents that accrue to the workers in one-shot interactions do not occur accidentally but are the result of a reasonable economic decision of the firms. One reason why the workers may get paid a rent in one-shot encounters, like, e.g., in period 15 of the ICF and in all periods of the ICR, is the existence of reciprocal workers. In the presence of fair workers it may be profitable for the firms to make generous contract offers even in one-shot encounters to induce fair workers to choose non-minimal effort levels. The next result shows that this is indeed the case.

Result 10: It is profitable for the firms to pay rents in one-shot encounters because the relation between effort and wage is sufficiently steep. Both in the ICR-condition and in the final period of the ICF-condition the workers earn substantial rents. 
The profitability of paying a rent in one-shot encounters is shown in Figure 9, which depicts the relation between the firms' material payoff and the workers' current rents in the ICR-condition. The workers' current rents are computed as the difference between the workers current income from trading and the unemployment benefit of 5 . The figure shows a "concave" relation between the firms' material payoff and the workers' rents. For rents up to 30 the firms' payoff is increasing in the workers' rents. For higher rents it is decreasing. We have computed the same relation for period 15 of the ICF and found similar results. Initially the firms' profit is increasing in the workers' rent and for higher rent levels it is decreasing.

FIGURE 9: Relation between firms' profits and workers' rents in the ICR-condition

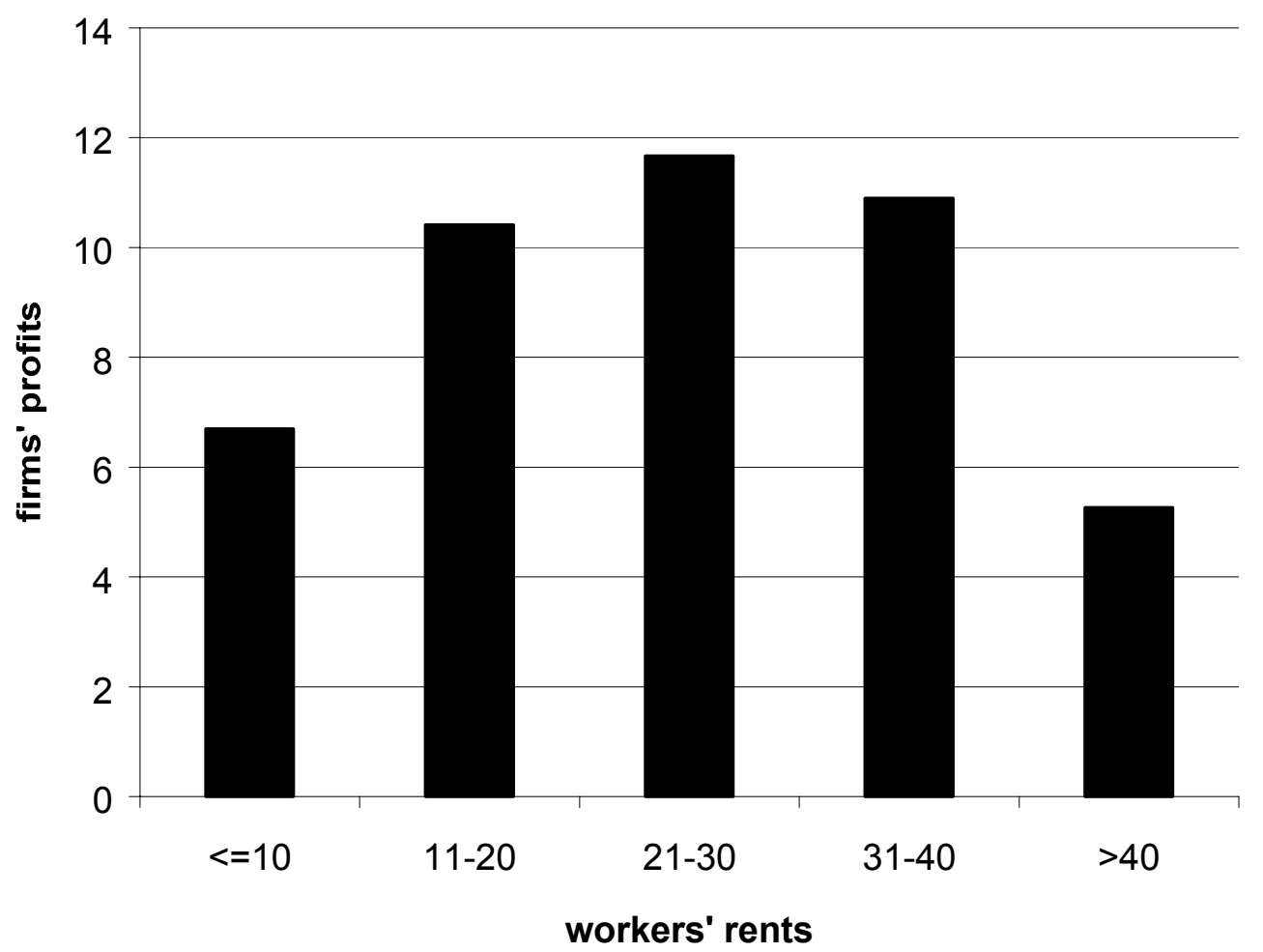

Our previous results suggest that the firms' contingent renewal policy was a very powerful effort elicitation device. Since the total surplus is monotonically increasing in the effort level the possibility of contingent renewal in the ICF led to a clear increase in the total gains from trade relative to the ICR. This raises the question how this increase in the gains from trade is distributed between firms and workers. Do both parties benefit from the increase in the gains from trade or does only one party benefit, perhaps even at the expense of the other? 
Result 11: On average, both the firms and the workers are better off in the ICF-relative to the ICR-condition. The firms gain more from the increase in the gains from trade than the workers.

Figure 10 reveals the time trend of the firms' profits and the workers' rents per trade in both conditions. In all periods except period 15 the firms earn much more in the ICF than in the ICR. In the final period they still earn more in the ICF but the difference is not as large as in the other periods. In the ICR the firms' profits vary between 5 and 13 while in the first 14 periods of the ICF their profits vary between 21 and 36 . There can thus be little doubt that the possibility of forming long-term relations benefits the firms. This is also supported by a Mann Whitney test ( $p$ $=0.0143$ ) with session averages as the units of analysis. Yet, Figure 10 also shows that the workers do better in every period of the ICF compared to the ICR. While at the beginning the difference in the workers' rents across conditions is relatively small, over time the difference becomes quite large. A Mann Whitney test shows that the difference in workers' rents per trade across conditions is significant ( $p=0.05$ with session averages as the units of analysis). Thus, the ICF-condition represents a Pareto-improvement relative to the ICR.

FIGURE 10: Time trend of firms' profits and workers' rents per trade in the ICF- and the ICR-condition

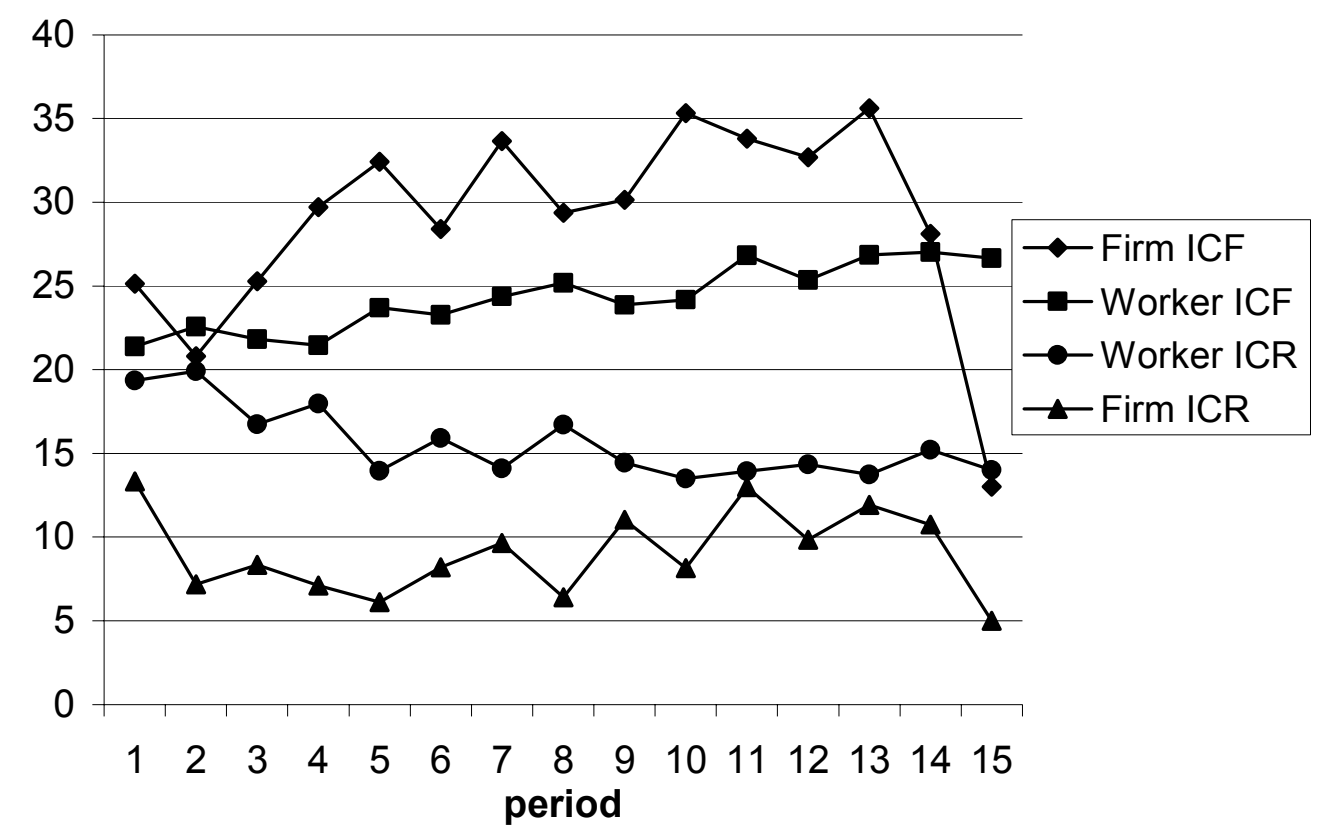


It is also interesting that both the firms' profits and the workers' rents increase over time in the ICF. This neatly shows that both trading parties gain from the steady increase in the effort level that occurs in the ICF. In the final period there is a large drop in the firms' profit, which is caused by the effort reduction. This effort reduction is consistent with the view that the material incentives that were generated by the firms' contingent renewal policy were responsible for the high performance in the ICF relative to the ICR. In the final period contingent renewal no longer works and, hence, selfish worker can no longer be disciplined. The effort reduction in the final period should, however, not make us overlook the fact that even in the absence of contingent renewal non-minimal effort levels have been enforced because a substantial fraction of the workers still reciprocated even in one-shot encounters (i.e., in the ICR and the final period of the ICF).

The relatively high rents of the workers in all the periods of the ICF-condition are interesting for three reasons. First, they indicate that in all the periods unemployment was involuntary because the unemployed workers would have been better off if they had had a job. Moreover, as the very low rents for employed workers in the C-condition show, the unemployed workers would have been willing to work at substantially lower wages. Second, the high rents show that the entrance fee critique against the disciplining version of the efficiency wage hypothesis does not apply here. This critique says that any rent that is earned by the workers in future periods will be extracted up-front by the firms by charging an entrance fee (Carmichael 1985). While it was not possible to charge an entrance fee in our experiment it was possible to pay wages of zero. By paying $w=0$ in period $t$ and demanding the maximum effort the firms could at least extract part of the huge future rents from the workers. However, there is simply no evidence that firms ever tried such a policy. Instead firms attempted to share the total gains from a trade in each period. Except for periods 2 and 15 the workers' share in the gains from trade varied between 42 and 49 percent (in period 2 and 15 it was even above 50 percent). In view of the workers' behavior the firms' sharing policy was quite rational because the workers' effort choice in $t$ strongly varied with the wage in $t$. Thirdly, the high rents provide a rationale for the absence of disagreements about contract conditions in the ICF. In the C-condition the firms took advantage of the excess supply of workers and their attempts to enforce low wages led to a considerable rejection of offers. In the ICF-condition the workers had little reason to bargain about the terms of the contract because the firms did offer contracts with rather high rents. 


\section{Conclusions}

In this paper we have shown that contractual incompleteness and the associated enforcement problems change the nature of market interactions in a fundamental manner. When contracts are complete the identity of the trading partner is irrelevant and the vast majority of trades takes place in one-shot transactions. The short side of the market uses its bargaining power to squeeze the long side of the market, which creates considerable disagreement on contract terms. In contrast, when contracts are incomplete, firms care about the identity of their workers. They voluntarily constrain the set of trading partners by restricting their offers exclusively to particular workers with whom they trade repeatedly. Workers typically earn considerable rents and there is little disagreement on the terms of the contract. Firms implement a policy of contingent contract renewal that rewards high and satisfactory performance with the renewal of the contract. When we remove the opportunity of renewing the contract with the previous worker there is a substantial drop in the average effort and the minimal effort becomes the most frequently chosen effort level. Under incomplete contracts firms have little incentives to extract current or future rents from the workers by low offers because this leads to an immediate reduction in the effort level. Both the firms and the workers are better off if they are allowed to engage in long-term relations.

We also find evidence suggesting that workers accumulate reputational capital and become more loyal to their firms in the course of long-term relations. In longer lasting relations firms expect higher effort levels and they experience less subjective uncertainty regarding effort realization. Moreover, workers in longer lasting relations do indeed provide higher effort levels making firms, ceteris paribus, more reluctant to fire them.

We believe that, apart from the insights provided by this paper, there are also methodological returns from our experiments. With appropriate modifications and additional treatment conditions our experimental set-up can be used to examine a host of other interesting questions. In our framework, for instance, one could easily study the market and efficiency consequences of employment legislation rendering layoffs costly for the firms. Another interesting question is what happens if firms receive information on the unemployment history of the workers. Do workers who have been unemployed for prolonged periods of time get stigmatized, i.e., do they get fewer and worse offers? A further important questions is how markets work in which the sellers can acquire a general reputation for being trustworthy. In our experiments the workers could only acquire a relation-specific reputation because the other firms did not know how well a particular worker worked. While this is a natural set-up for many labor markets, there are clearly many goods markets in which the sellers have the opportunity to 
acquire a general reputation. Moreover, one could allow the sellers to invest into costly advertising to create a general reputation.

Also, questions regarding the interaction between explicit and implicit incentives have remained largely unexplored empirically. For instance, is it indeed the case that the availability of better explicit incentives makes self-enforcing agreements less likely - as hypothesized by Baker, Gibbons and Murphy (1994) and Schmidt and Schnitzer (1995). Or: How do decisions with regard to vertical integration interact with relational contracts (Baker, Gibbons and Murphy 2002)?

Finally, our set-up lends itself to the analysis of the question to what extent self-enforcing implicit agreements are associated with price or wage stickiness. In our view it may well be that the existence of long-term relations introduces considerable inertia into the system. Our results suggest that long-term relations are embedded into a system of implicit obligations and beliefs about obligations that render fairness concerns prominent. Once a worker and a firm have established a long lasting implicit agreement fairness concerns and the coordination problems involved in reaching a different implicit agreement may render the parties unwilling to change the agreement despite the existence of supply or demand shocks. 


\section{References}

Akerlof, G. A. (1982): "Labor Contracts as Partial Gift Exchange", Quarterly Journal of Economics 97, 543-69.

Akerlof, G. A. and Yellen, J. L. (1990): "The Fair Wage- Effort Hypothesis and Unemployment", Quarterly Journal of Economics, 105, 255-283.

Baker, G., Gibbons, R. and Murphy K. J. (1994): "Subjective Performance Measures in Optimal Incentive Contracts", Quarterly Journal of Economics 109, 1125-56.

Baker, G., Gibbons, R. and Murphy K. J. (2002): "Relational Contracts and the Theory of the Firm", Quarterly Journal of Economics 117, 39-84.

Banerjee, A. Duflo, E. (2000): "Reputation Effects and the Limits of Contracting: A Study of the Indian Software Industry”, Quarterly Journal of Economics CXV, 989-1017.

Bolton, G. E. and Ockenfels, A. (2000): "A theory of equity, reciprocity and competition" American Economic Review 100, 166-193.

Bowles, Samuel (1985): "The Production Process in a Competitive Economy: Walrasian, NeoHobbesian, and Marxian Models", American Economic Review, vol. 75, No. 1, 16 - 36.

Bowles, S., Gordon, D. M. and Weisskopf, T. E. (1983): "Hearts and Minds: A Social Model of U.S. Productivity Growth”, Brookings Papers on Economic Activity, 1983 (2), 381-441.

Bull, C. (1987): "The Existence of Self-Enforcing Implicit Contracts" Quarterly Journal of Economics 102, 147-159.

Camerer, C. (forthcoming): "Behavioral Game Theory", Princeton University Press, Princeton 2001.

Camerer, C. and Thaler, R. (1995): "Ultimatums, Dictators, and Manners", Journal of Economic Perspectives 9, 209-219.

Carmichael, L. (1985): "Can Unemployment be Involuntary ?" American Economic Review 75, $1213-14$.

Charness, G., and Rabin, M. (2000): "Social Preferences: Some Simple Tests and a New Model" Mimeo, University of California at Berkeley.

Crocker, K. and Reynolds, K. (1993): "The Efficiency of Incomplete Contracts: An Empirical Analyisis of Air Force Engine Procurement", RAND Journal of Economics XXIV, 127146.

Dixit, A. (2001): "On Modes of Economic Governance", CESifo Working Paper Series No. 589.

Dufwenberg, M. and Kirchsteiger, G., (1998): “A Theory of Sequential Reciprocity” Discussion Paper. CentER, Tilburg University.

Falk, A. and Fischbacher, U., (1999): “A Theory of Reciprocity" Institute for Empirical Research in Economics, University of Zurich, Working Paper No. 6

Fehr, E. and Gächter, S. (2000): "Fairness and Retaliation - The Economics of Reciprocity", Journal of Economic Perspectives 14, 159-181.

Fehr, E., Gächter, S., and Kirchsteiger G. (1997): "Reciprocity as a Contract Enforcement Device: Experimental Evidence", Econometrica 65, 833-860.

Fehr, E. and K. M. Schmidt, 1999: "A Theory of Fairness, Competition and Co-operation", Quarterly Journal of Economics 114, 817-868.

Fischbacher U. (1999): “z-Tree: Experimental Software”, University of Zurich.

Fudenberg, D. and Maskin E. (1986): “The Folk Theorem for Repeated Games with Discounting and Incomplete Information", Econometrica, 54, 533-54

Gibbons, R and Katz, L. (1992): "Does Unmeasured Ability Explain Inter-Industry Wage Differences?", Review of Economic Studies 59, 515-35. 
Gintis, H. (1976): “The Nature of the Labor Exchange and the Theory of Capitalist Production", Review of Radical Political Economics 8, 36-54.

Grossman, S. and Hart, O. (1986): "The Costs and Benefits of Ownership: A Theory of Vertical and Lateral Integration”, Journal of Political Economy, 94, 691-719.

Hart, O. (1995): Firms, Contracts, and Financial Structure, Oxford University Press.

Hart, O. (2001): "Norms and the Theory of the Firm", NBER Working Paper No. 8286.

Hart, O. and Holmström, B. (1987): "The Theory of Contracts", in Advances in Economic Theory, Fifth World Congress, edited by Truman Bewley. Cambridge: Cambridge University Press, 1987.

Kirchsteiger, G., Niederle, M. and Potters, J. (2001): "Public versus Private Exchanges", mimeo, University of Vienna.

Klein B. and Leffler, K. B. (1981): "The Role of Market Forces in Assuring Contractual Performance", Journal of Political Economy 89, 615-641.

Kollock, P. (1994): "The Emergence of Exchange Structures: An Experimental Study of Uncertainty, Commitment, and Trust", American Journal of Sociology 100, 313-45.

Kreps, D., Milgrom, P., Roberts, J., and Wilson, R. (1982): "Rational Cooperation in the Finitely Repeated Prisoners' Dilemma”, Journal of Economic Theory 27, 245-252.

Kruger, A. B., Summers, L. (1988): "Efficiency Wages and the Inter-Industry Wage Structure", Econometrica, 56, 259-94.

Levine, D. (1998): "Modeling Altruism and Spitefulness in Experiments", Review of Economic Dynamics 1, 593-622.

MacLeod W. B. and Malcomson, J. M. (1989): "Implicit Contracts, Incentive Compatability and Involuntary Unemployment", Econometrica 57, 447-480.

MacLeod, W.B. and Malcomson, J. M. (1993): "Wage premiums and profit maximization in efficiency wage models, European Economic Review 37, 1223-1249.

MacLeod W. B. and Malcomson, J. M. (1998): "Motivation and Markets", American Economic Review 88, 388-411.

Malcomson, J. M. (1999): “Individual Employment Contracts", Handbook of Labor Economics, vol. 3b, ed. by Orley C. Ashenfelter and David Card, North-Holland, 1999.

McMillan, J. and Woodruff, C. (1999): "Interfirm Relationships and Informal Credit in Vietnam, Quarterly Journal of Economics CXIV, 1285-1320.

Murphy, K. M. and Topel, R. H. (1990): "Efficiency Wages Reconsidered: Theory and Evidence", in: Weiss Y. and Fishelson G. (eds.), Advances in the Theory and Measurement of Unemployment, London, Macmillan.

Rabin, M. (1993): "Incorporating Fairness into Game Theory and Economics", American Economic Review 83, 1281-1302.

Roth, A. E. (1995): "Bargaining Experiments", in: J. Kagel and A. Roth (eds.): Handbook of Experimental Economics, Princeton, Princeton University Press.

Rubinstein, A. and Wolinsky A. (1990): "Decentralized Trading, Strategic Behaviour and the Walrasian Outcome", Review of Economic Studies 57, 63-78.

Samuelson, W. and Zeckhauser, R. (1988): "Status Quo Bias in Decision Making”, Journal of Risk and Uncertainty 1, 7-59.

Schmidt, K. and Schnitzer, M. (1995): “The Interaction of Explicit and Implicit Contracts", Economic Letters, 48, 193-199.

Shapiro, C. and Stiglitz, J. E. (1984): "Equilibrium Unemployment as a Worker Discipline Device”, American Economic Review, vol. 74, No. 3, 433 - 44.

Williamson, O. E. (1985): The Economic Institutions of Capitalism, New York: The Free Press. 


\section{Appendix 1}

In this appendix we show in more detail how high effort levels can be sustained in a perfect Bayesian equilibrium in the ICF condition if sufficiently many fair subjects who reciprocate generous contract offers with generous effort levels are present. For tractability reasons our argument relies on the theory of fairness developed by Fehr and Schmidt (1999). In the twoplayer case the utility function of fair players is thus given by

$$
U_{i}(x)=x_{i}-\alpha_{i} \max \left\{x_{j}-x_{i}, 0\right\}-\beta_{i} \max \left\{x_{i}-x_{j}, 0\right\},
$$

$i \in\{1,2\}, i \neq j$, where $x=\left(x_{1}, x_{2}\right)$ denotes the vector of monetary payoffs and $\beta_{i} \leq \alpha_{i}, 0 \leq \beta_{i}<1$. The term weighted with $\alpha_{i}$ measures the utility loss that stems from inequality to $i$ 's disadvantage, while the term weighted with $\beta_{i}$ measures the loss from advantageous inequality. We use a grossly simplified version of this theory. We assume that there are 40 percent selfinterested types $\left(\alpha_{i}=\beta_{i}=0\right)$ and 60 percent fair types. Fair subjects exhibit $\alpha_{i}=\beta_{i}=0.5+\varepsilon$, where $\varepsilon$ is a small positive number. Fair subjects thus have a willingness to pay in order to achieve equality. If the inequality is to their disadvantage, they are prepared to engage in costly "punishment" in order to reduce the payoff of their opponent. If the inequality is to their advantage, they are willing to spend resources in order to benefit the other player. Subjects with $\alpha_{i}=\beta_{i}=0.5+\varepsilon$ are willing to share the surplus of a contract equally.

For our application we make two further simplifying assumptions. We assume that, once a contract has been accepted, the only reference agent for a subject in our experiment is his or her trading partner. This allows us to use the above two-person utility function to study the effort behavior of the workers. We believe that this assumption well approximates the subjects' perception of the situation because they do not know the effort that is provided in other trades. In addition, once a contract has been concluded the trading partner has clearly a salient position for a subject in our experiment. We also assume that each firm can make exactly one offer, private or public, per period and that the firms' offers are made simultaneously. We make this assumption for reasons of tractability. The strategy space of continuous auctions, in which many firms and workers interact and in which the traders continuously can make offers during the trading period, is so large that this institution has so far defied a fully rigorous analysis. Therefore, we approximate this institution by a posted contract institution in which each firm simultaneously makes one offer per period.

On the basis of the above assumptions it can be shown that the following strategies are part of a perfect Bayesian equilibrium in the ICF-condition. The strategy of the workers is as follows: In all periods the fair workers choose the payoff equalizing effort level. They accept any contract that gives them a non-negative payoff. The selfish workers also accept any contract that give them a non-negative material payoff. They perform at the desired effort level if the cost of the desired effort in period $t-1$ is less than or equal to the expected loss from being fired. 
The firms' strategy is as follows: In all periods a firm renews the contract with the previous worker if the worker provided the desired effort level. Otherwise, the worker does not get a new offer from his previous firm. Firms make a public offer in period 1, and whenever they do not renew the contract of the previous worker. From period 1 to 13 all firms offer a contract $(\mathrm{w}, \widetilde{e})=(59,10)$. This contract equalizes the material payoff if the worker chooses $e=10$. In period 14 all firms offer the contract $(\mathrm{w}, \widetilde{e})=(40,7)$. This contract equalizes the material payoff if the worker chooses $e=7$. In period 15 the selfish firm offers $(\mathrm{w}, \widetilde{e})=(34,6)$ while the fair firm offers $(\mathrm{w}, \widetilde{e})=(5,1)$. Both contracts again equalize the material payoffs of the trading parties if the worker provides the desired effort level. Note that the period-15-contract of the fair firms gives all workers a payoff of 5 , which is identical to the unemployment benefit of 5 . This contrasts with the contract of the selfish firms. This contract gives the fair workers a payoff of 26 , and the selfish workers (who shirk in the final period) a payoff of 34 .

The strategies described above are supported by out-of-equilibrium beliefs of the workers that the firm terminates the relation at the end of the period if it does not pay a "fair" wage in this period. The "fair" wage is the wage that equalizes the payoff if the worker chooses the desired effort level $\widetilde{e}$. If, however, the firm pays a fair wage in period $t$, the worker believes that he will get a new offer in period $t+1$ with probability 1 .

The crucial intuition behind this equilibrium is the existence of a rent in period 15 . Note that when all subjects are selfish firms have no incentive to offer a rent in period 15 . In the presence of fair workers, however, the selfish firms have an incentive to pay a relatively high wage in period 15 because the fair workers respond to high wages in any given period $t$ with payoff equalizing effort levels in period $t$. This makes it profitable for the selfish firms to pay a high wage in period 15. In contrast, the fair firms do not pay a high wage in period 15 because they derive extra disutility from the shirking of the selfish workers. The reason is that shirking causes inequality to the disadvantage of the firm, which is negatively valued by fair firms. Thus, in period 15 the fair workers induce the selfish firms to pay a high wage while the selfish workers induce the fair firms to pay a low wage.

To be more precise recall that, by assumption, there are 60 percent fair types and 40 percent selfish types. For any given wage the fair workers prefer an effort level that equalizes $\pi_{f}$ and $\pi_{w}$, i.e., an effort such that $10 e-w=w-c(e)$ holds. Differentiating yields $\partial e / \partial w=2 /\left[10+c^{\prime}(e)\right]$. We consider first the effort and wage decisions in period 15 . Remember that in equilibrium the workers' type is not yet revealed when the firms decide on their contract offer in $t=15$. The expected material payoff of a firm, which does not know the type of the worker, is $E \pi_{f}=0.6[10 e(w)-w]+0.4[10-w]$ where $e(w)$ denotes the fair worker's effort level. Differentiation with suspect to $\mathrm{w}$ yields $\partial E \pi_{f} / \partial w=6(\partial e / \partial w)-1=\left[12 /\left(10+c^{\prime}(e)\right)\right]-1$. This derivative is zero if $c^{\prime}(e)=2$, which is the case for all $e \in\{3,4, \ldots, 8\}$. Thus, the firm's profit is the same for all wages that induce effort levels in the set $\{3,4, \ldots, 8\}$. They all give an expected profit of $E \pi_{f}=6$. This means that the selfish firm is indifferent between any $\widetilde{e} \in\{3,4, \ldots, 8\}$. The fair 
firm, however, prefers $\tilde{e}=1$ and $w=5$. This gives her an expected utility of $E U_{f}=10 \cdot 1-5=5$. For any $\widetilde{e}>1$ the selfish worker will shirk which causes disadvantageous inequality for the fair firm. For example, to induce fair worker to choose $\widetilde{e}=3$ a firm has to pay $w=(30+2) / 2=16$. The expected utility of this wage offer is $E U_{f}=E \pi_{f}-0.4 \alpha[16-(10-16)]=6-8.8 \alpha$. The term in the brackets is the payoff difference between $\pi_{w}$ and $\pi_{f}$ if the worker shirks, which happens with probability 0.4 . It is easy to see that for $\alpha \geq 1 / 2, E U_{f}<5$, i.e., the fair firm prefers $\widetilde{e}=1$ over $\widetilde{e}=3$. The same holds for all wages inducing $\widetilde{e}>1$. Thus while (w, $\widetilde{e})=(5,1)$ is the utility maximizing offer for fair firms in $t=15$, $(\mathrm{w}, \widetilde{e})=(34,6)$ is a (non-unique) utility maximizing offer for selfish firms. The rest of our argument is based on the assumption that selfish firms offer $(34,6)$ in $t=15$ but in view of the non-uniqueness of the best offer different assumptions would be equally legitimate.

In order to compute the expected loss of the workers from shirking in $t=14$ it is important to recall that in $\mathrm{t}=14$ the workers do not know the type of their firm. They thus do not know for sure which offer they will receive in $\mathrm{t}=15$ in case that they meet the desired effort in $t$ $=14$. Since there are 60 percent fair firms and 40 percent selfish firms a fair worker, who does not know the type of his firm, has an expected payoff of $E \pi_{w}=0.6 \cdot 5+0.4[34-8]=13.4$ in period 15. A selfish worker, who does not know the type of his firm, has an expected payoff of $E \pi_{w}=0.6 \cdot 5+0.4[34-0]=16.6$ in period 15 . Therefore the payoff gain from being employed in the final period is $16.6-5=11.6$ for the selfish worker and $13.4-5=8.4$ for the fair worker. ${ }^{23}$ This means that the implicit threat of firing the worker in case he shirks in $t=14$ induces a selfish worker to provide up to $\widetilde{e}=7$ in period 14. The selfish worker prefers, however, to shirk if the firm demands $\widetilde{e}>7$ in $t=14$ because $\mathrm{c}(\widetilde{e}) \geq 12$ for $\widetilde{e}>7$.

Given the behavior of the selfish worker it is optimal for all firms to demand $\widetilde{e}=7$ in $t=14$ and pay the payoff-equalizing wage of $w=40$ for that effort level. It does not pay to offer $w>40$ because only fair workers will reward this and it also does not pay to offer $w<40$. In the latter case the workers believe that the contract will not be renewed in $t=15$. Therefore $w<40$ induces full shirking of the selfish worker and - depending on the value of $\mathrm{w}-$ partial shirking $(1<e<\widetilde{e}=7)$ of the fair worker. It is also obvious that in case of $e=\widetilde{e}$ in $t$ the firm must make a private offer to the previous worker because otherwise the firm risks to be paired with a new worker in $t+1$. Since this would be anticipated it would dilute the incentives of the selfish worker in $t$.

If a worker has shirked and the firm does not renew the contract with this worker the firm is indifferent between a private and a public offer, i.e., the public offer is also optimal. In $t=13$ the expected rent from employment in the final two periods for a selfish worker is $[(40-10)-5]+11.6=36.6$. This means that in $t=13$ the selfish worker can be induced to provide $\tilde{e}=10$ because $c(10)=18<36.6$. Therefore, it is optimal for all firms to offer contracts

\footnotetext{
${ }^{23}$ Note that the probability of getting reemployed by a different employer, after a unilateral deviation from the equilibrium effort, is zero because, in equilibrium, all other employers renew the contracts with their previous workers.
} 
$(w, \widetilde{e})=(59,10)$ in $t=13$. By backward induction this is also the optimal offer in all previous periods. The fair workers choose $e=\widetilde{e}=10$ because at $w=59$ this is the fair choice while selfish workers choose $e=10$ because the threat of not getting the contract renewed provides enough incentives.

Finally, note that accepting any offer with a non-negative payoff is rational for a fair worker as long as the worker believes that there are selfish unemployed workers. Since the selfish workers accepts any non-negative payoff a fair worker can never punish a firm by rejecting a low offer.

The previous argument shows that in the first 13 periods it is possible to sustain the maximum effort level in the ICF. Since in the ICR only one-shot interactions can take place the maximum effort level cannot be enforced. 


\section{Appendix 2}

Appendix 2 contains the English translation of the German instructions for the ICF-treatment. Except for the treatment differences, the instructions for the ICR-and the C-treatment were exactly like the ICF-instructions.

\section{Instructions for Buyers}

You are now taking part in an economic experiment. Please read the following instructions carefully. Everything that you need to know in order to participate in this experiment is explained below. Should you have any difficulties in understanding these instructions please notify us. We will answer your questions at your cubicle.

At the beginning of the experiment you will receive an initial endowment of 10 Swiss Francs. During the course of the experiment you can earn a further amount of money by gaining points. The amount of points that you gain during the experiment depends on your decisions and the decisions of other participants.

All points that you gain during the course of the experiment will be exchanged into Swiss Francs at the end of the experiment. The exchange rate will be:

\section{1 point $=0.15$ Swiss Francs}

At the end of the experiment you will receive the money that you earned during the experiment in addition to your endowment of 10 Francs.

The experiment is divided into periods. In each period you have to make decisions, which you will enter on a computer screen. There are 15 periods in all.

Please note that communication between participants is strictly prohibited during the experiment. In addition we would like to point out that you may only use the computer functions which are required for the experiment. Communication between participants and unnecessary interference with computers will lead to the exclusion from the experiment. In case you have any questions don't hesitate to ask us.

Prior to the experiment the 17 participants were divided into 2 groups: buyers and sellers. In this experiment there are 10 sellers and 7 buyers.

You are a buyer throughout the whole experiment. All participants have received an identification number which they will keep for the entire experiment. Your identification number is stated on the documentation sheet in front of you.

\section{An Overview of the Experimental Procedures}

In each period of the experiment every buyer can buy a product from a seller. The seller earns a profit by trading if he sells the product at a price, which exceeds his production costs. The buyer earns a profit by trading if the price he pays for the product is less than what the product is worth to him. The production costs and the product's value for the buyer depend on the quality of the product.

The experiment lasts for 15 periods. In each period the procedures are as follows:

1. Each period starts with a trading phase which lasts 3 minutes. During this phase buyers can submit offers, which can be accepted by sellers. When submitting an offer a buyer has to specify three things:

- which price he offers to pay,

- which product quality he desires,

- $\quad$ and finally, which seller he wants to submit the offer to. Buyers can submit two types of offers; private offers and public offers. Private offers are submitted to one seller only and can only be accepted by that seller. Public offers are submitted to all sellers and can be accepted by any seller. 
As a buyer you can - in each period - submit as many offers as you like. Submitted offers can be accepted at any time during the trading phase. Each buyer and each seller can at most conclude one trade in each period.

As there are 10 sellers and 7 buyers, several sellers will not trade in each period.

2. Following the trading phase each seller who has concluded a trade determines which product quality he will supply. The seller is not obliged to supply the product quality desired by his buyer. Once every seller has chosen a product quality each participant's earnings in the current period are determined. After this the next period starts.

The points gained from all 15 periods will be summed up at the end of the experiment, exchanged into Swiss Francs and paid together with your endowment in cash.

\section{The Experimental Procedures in Detail}

There are 7 buyers and 10 sellers in the experiment. You are a buyer throughout the whole experiment. During the experiment you will enter your decisions on a computer screen. In the following we describe in detail how you can make your decisions in each period.

\section{The Trading Phase}

Each period starts with a trading phase. During the trading phase each buyer can conclude a trade with a seller. In order to do so each buyer can submit as many offers as he wishes. In each trading phase you will see the following screen:

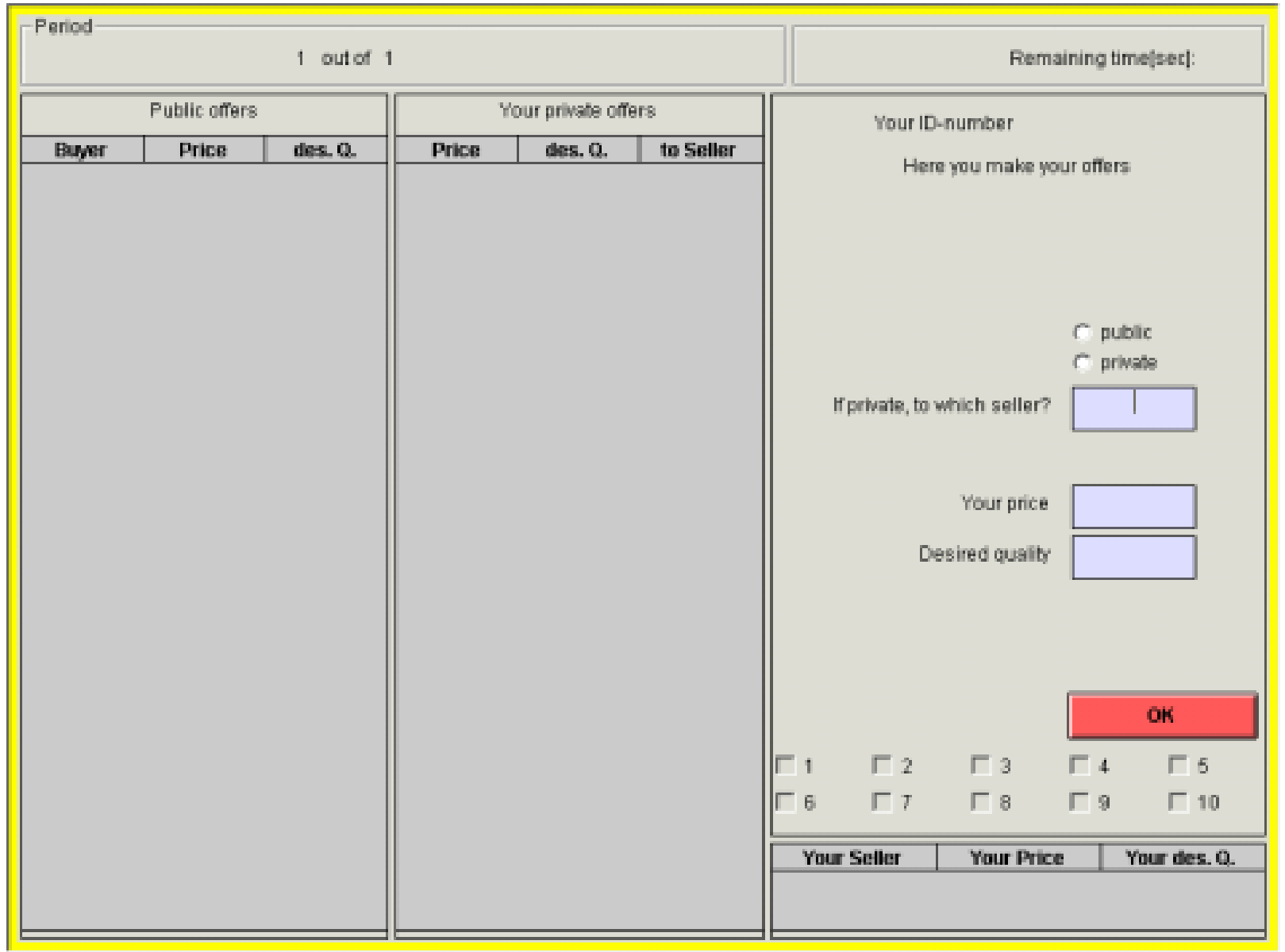

- In the top left corner of the screen you see in which period of the experiment you are. In the top right corner of the screen you will see the time remaining in this trading phase, displayed in seconds. The trading phase in 
each period lasts 3 minutes (= 180 seconds). When this time is up the trading phase is over. Hereafter, no further offers can be submitted or accepted in this period.

- Once the above screen is displayed the trading phase starts. As a buyer you now have the opportunity to submit offers to the sellers. In order to do so you have to enter three things on the right hand side of the screen:

a) First you have to specify whether you want to submit a public or a private offer:

- Public trade offers

Public offers will be communicated to all participants in the market. All sellers see all public offes on their screens. A public offer can therefore be accepted by any seller. As a buyer you will also see all public offers submitted by all buyers.

If you want to submit a public offer, click on the field "public", using the mouse.

\section{- Private trade offers}

A private offer is submitted to one seller only. Only this seller is informed about the offer and only this seller can accept the offer. No other seller or buyer will be informed about that offer.

If you want to submit a private offer, click on the field ,private“ using the mouse. After that you specify which seller you want to submit the offer to in the field below. Each of the 10 sellers has an identification number (seller 1, seller 2, ....., seller 10). Each seller keeps his identification number throughout the whole experiment. To submit an offer to a specific seller you enter the number of that seller (e.g., "4" for seller 4).

b) Once you have specified to whom you want to submit an offer, you must determine which price you offer. You enter this in the field "Your price". The price you offer is a number between 0 and 100:

\section{$0 \leq$ price offered $\leq 100$}

c) Finally you have to specify which product quality you desire. You enter this in the field "Desired quality". Your desired quality is a number between 1 and 10 :

$$
1 \leq \text { desired quality } \leq 10
$$

After you have completely specified your offer, you must click on the "OK" button to submit it. As long as you have not clicked "OK" you can change your offer. After you click "OK" the offer will be displayed to all sellers you have submitted it to.

- $\quad$ On the left side of your screen you see the header "public offers". All public offers in the current trading phase are displayed here. Your public offers as well as those of all other buyers will be displayed. You can see which buyer submitted the offer, which price he offered and which quality he desired. All buyers also have an identification number, which they keep throughout the whole experiment.

- In the middle of your screen under the header "Your private offers". You see all private offers, which you have submitted in the current trading phase. You see which price you offered, which quality you desired and which seller you submitted an offer to.

- Each buyer can submit as many private and public offers as he wishes in each period. Each offer that you submit can be accepted at any time during the trading phase.

- In any given period each buyer can conclude at most one trade. Once one of your offers has been accepted you will be notified which seller accepted which of your offers. In the bottom right corner of your screen the identification number of the seller will be displayed as well as your offered price and your desired quality. As you can conclude only one trade in each period all your other offers will be automatically cancelled. Also, you will not be able to submit any further offers.

- In any given period each seller can conclude at most one trade. You will be continuously informed which sellers have not yet accepted an offer. On the right bottom of the screen you see 10 fields, each field for one of the ten sellers. Once a seller has accepted an offer a „x“ will appear in the field next to the seller's identification number. You cannot submit private offers to a seller who has already concluded a trade. 
- Once all 7 buyers have concluded a trade or after 3 minutes have elapsed, the trading phase is over.

- No buyer is obliged to submit offers, and no seller is obliged to accept an offer.

\section{Determination of the Product Quality}

- $\quad$ Follwoing the trading phase, all sellers who have concluded a trade determine which product quality they supply to their respective buyers. The product quality, which you desired in your offer, is not binding for your seller. Your seller can choose the exact quality you desired, but he can also choose a higher or a lower product quality. The product quality which your seller chooses has to be between 1 and 10:

\section{$1 \leq$ product quality $\leq 10$}

- While your seller determines the actual product quality, we ask you to specify which quality you expect him to supply on a separate screen. In addition we ask you to state how sure you are about this expectation.

\section{How are the Incomes Calculated?}

\section{Your income:}

- If you do not conclude a trade during a trading phase you receive an income of 0 points in that period.

- If one of your offers is accepted, your income depends on the price you offered and on the product quality. Your income is determined as follows:

\section{Your income $=10 *$ product quality - price}

- As you can see from the above formula your income is higher, the higher the product quality actually supplied by your seller. At the same time your income is higher, the lower the price you paid for the product.

\section{Income of your seller}

- If a seller has not concluded a trade during a trading phase he gains an income of 5 points in that period.

- If a seller has accepted an offer his income equals the price he receives minus the production costs he incurs. The income of the seller is determined as follows:

Income of your seller $=$ Price - production costs

- The production costs of a seller are higher, the higher the quality he chooses. The production costs for each product quality are displayed in the table below:

\begin{tabular}{|l|l|l|l|l|l|l|l|l|l|l|}
\hline Product quality & 1 & 2 & 3 & 4 & 5 & 6 & 7 & 8 & 9 & 10 \\
\hline Production costs & 0 & 1 & 2 & 4 & 6 & 8 & 10 & 12 & 15 & 18 \\
\hline
\end{tabular}

- The income of your seller is higher, the higher the price. Further, his income is higher, the lower the product quality he supplies.

The income of all buyers and sellers are determined in the same way. Each buyer can therefore calculate the income of his seller and each seller can calculate the income of his buyer. Further, each buyer and seller is informed about the identification number of his trading partner in each period. 
Please note that buyers and sellers can incur losses in each period. These losses have to be paid from your initial endowment or from earnings made in other periods.

You will be informed about your income and the income of your seller on an "income screen". On the screen (see below) the following will be displayed:

- which seller you traded with

- which price you offered

- your desired quality

- the product quality actually chosen by your seller

- the income of your seller in this period

- your income in this period.

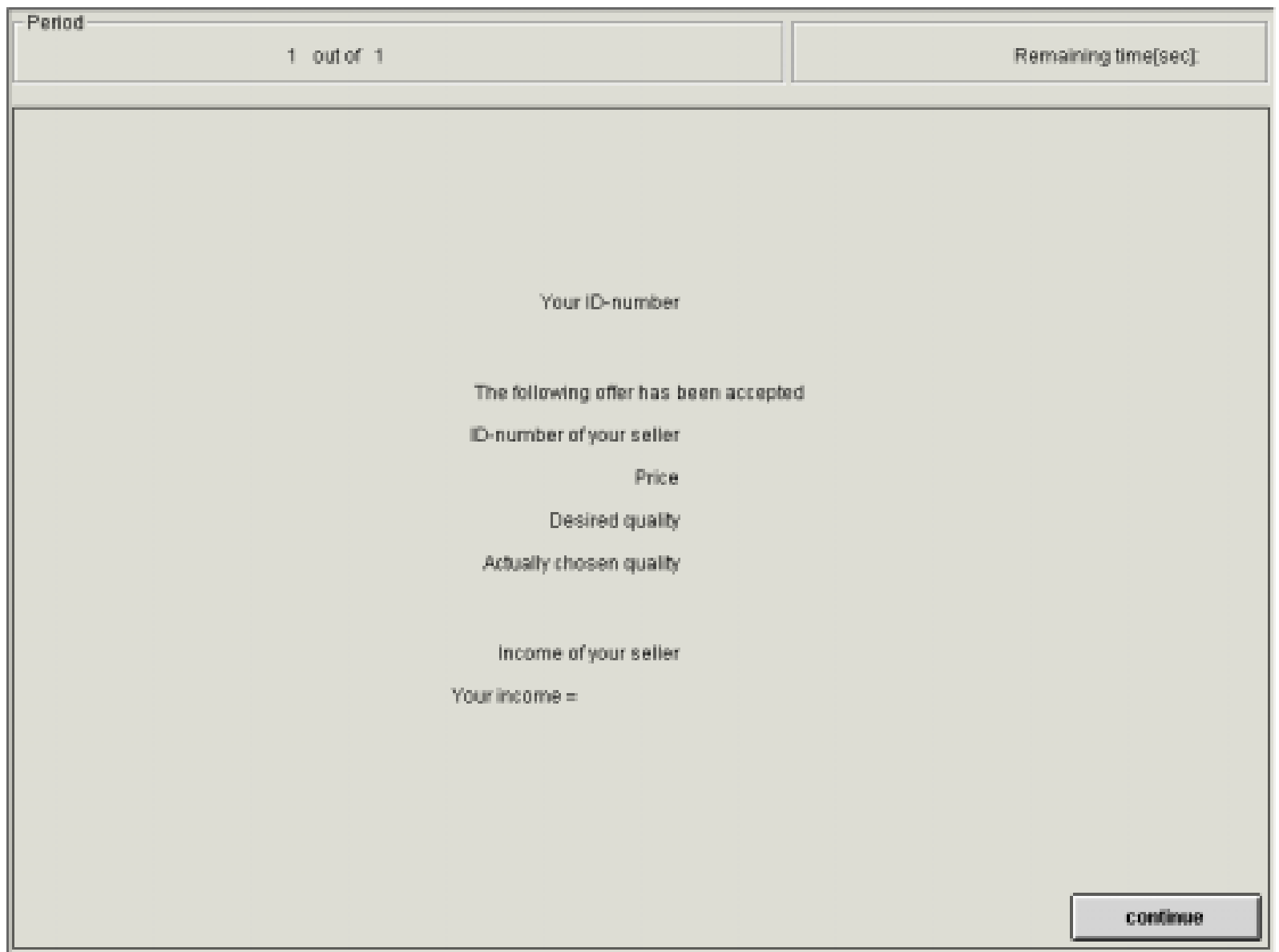

Please enter all the information in the documentation sheet supplied to you. After the income screen has been displayed, the period is over. Thereafter the trading phase of the following period starts. Once you have finished studying the income screen please click on the "continue" button.

The sellers also see an income screen, which displays the above information. They see the ID of their trading partner, the price, desired and actually supplied product quality as well as both incomes.

The experiment will not start until all participants are completely familiar with all procedures. In order to secure that this is the case we kindly ask you to solve the exercises below.

In addition we will conduct 2 trials of the trading phase, so that you can get accustomed to the computer. During the trial phases no money can be earned. After the trial phases we will begin the experiment, which will last for 15 periods. 


\title{
Control Questionnaire
}

Please solve the following exercises completely. If you have questions ask the experimenter.

\section{Exercise 1}

You did not make an offer during a trading phase. What is you income in this period?

Your income $=$

\section{Exercise 2}

You offered a price of 30 and indicated a desired quality of 9. A seller accepts your offer and actually chooses a quality of 8 .

\author{
Your income $=$ \\ Income of your seller $=$
}

\section{Exercise 3}

You offered a price of 60 and indicated a desired quality of 9. A seller accepts your offer and actually chooses a quality of 6 .

Your income $=$

Income of your seller $=$

\section{Exercise 4}

You offered a price of 10 and indicated a desired quality of 2. A seller accepts your offer and actually chooses a quality of 5.

$$
\begin{aligned}
& \text { Your income }= \\
& \text { Income of your seller }=
\end{aligned}
$$

\section{Exercise 5}

You offered a price of 10 and indicated a desired quality of 6 . A seller accepts your offer and actually chooses a quality of 2 .

$$
\begin{aligned}
& \text { Your income }= \\
& \text { Income of your seller }=
\end{aligned}
$$

\section{Exercise 6}

A seller did not accept an offer during a trading phase. What is the income of this seller in this period?

$$
\text { Income of your seller }=
$$

\section{Exercise 7}

You made several offers during a trading phase. None of your offers has been accepted by a seller. What is your income in this period?

$$
\text { Your income }=
$$

If you have finished the exercises we recommend to look again at the exercises and the solutions provided. After this please think about the decisions you want to make during the experiment. 


\section{Documentation sheet: Buyer}

This documentation sheet is meant for your orientation. Please complete the respective row in each period.

\begin{tabular}{|c|c|c|c|c|c|c|}
\hline period & $\begin{array}{l}\text { ID of your } \\
\text { seller }\end{array}$ & price & $\begin{array}{l}\text { desired } \\
\text { quality }\end{array}$ & actual quality & $\begin{array}{c}\text { income of your } \\
\text { seller }\end{array}$ & your income \\
\hline \multicolumn{7}{|l|}{1} \\
\hline \multicolumn{7}{|l|}{2} \\
\hline \multicolumn{7}{|l|}{3} \\
\hline \multicolumn{7}{|l|}{4} \\
\hline \multicolumn{7}{|l|}{5} \\
\hline \multicolumn{7}{|l|}{6} \\
\hline \multicolumn{7}{|l|}{7} \\
\hline \multicolumn{7}{|l|}{8} \\
\hline \multicolumn{7}{|l|}{9} \\
\hline \multicolumn{7}{|l|}{10} \\
\hline \multicolumn{7}{|l|}{11} \\
\hline \multicolumn{7}{|l|}{12} \\
\hline \multicolumn{7}{|l|}{13} \\
\hline \multicolumn{7}{|l|}{14} \\
\hline 15 & & & & & & \\
\hline
\end{tabular}




\section{Instructions for Sellers}

You are now taking part in an economic experiment. Please read the following instructions carefully. Everything that you need to know in order to participate in this experiment is explained below. Should you have any difficulties in understanding these instructions please notify us. We will answer your questions at your cubicle.

At the beginning of the experiment you will receive an initial endowment of 10 Swiss Francs. During the course of the experiment you can earn a further amount of money by gaining points. The amount of points that you gain during the experiment depends on your decisions and the decisions of other participants.

All points that you gain during the course of the experiment will be exchanged into Swiss Francs at the end of the experiment. The exchange rate will be:

$$
1 \text { point }=0.15 \text { Swiss Francs }
$$

At the end of the experiment you will receive the money that you earned during the experiment in addition to your endowment of 10 Francs.

The experiment is divided into periods. In each period you have to make decisions which you will enter in a computer. In total there are 15 periods.

Please note that communication between participants is strictly prohibited during the experiment. In addition we would like to point out that you may only use the computer functions which are required for the experiment. Communication between participants and unnecessary interference with computers will lead to the exclusion from the experiment. In case you have any questions don't hesitate to ask us.

Prior to the experiment the 17 participants were divided into 2 groups: buyers and sellers. In this experiment there are 10 sellers and 7 buyers.

You are a seller throughout the whole experiment. All participants have received an identification number which they will keep for the entire experiment. Your identification number is stated on the documentation sheet in front of you.

\section{An Overview of the Experimental Procedures}

In each period of the experiment every buyer can buy a product from a seller. The seller earns a profit by trading if he sells the product at a price which exceeds his production costs. The buyer earns a profit by trading if the price he pays for the product is less than what the product is worth to him. The production costs and the product's value for the buyer depend on the quality of the product.

The experiment lasts 15 for periods. In each period the procedures are as follows:

3. Each period starts with a trading phase, which lasts 3 for minutes. During this phase buyers can submit trade offers which can be accepted by sellers. When submitting an offer a buyer has to specify three things:

- which price he offers to pay,

- which product quality he desires,

- $\quad$ and finally, which seller he wants to submit the offer to. Buyers can submit two types of offers; private offers and public offers. Private offers are submitted to one seller only and can only be accepted by that seller. Public offers are submitted to all sellers and can be accepted by any seller.

Buyers can - in each period - submit as many offers as they like. Submitted offers can be accepted at any time during the trading phase. Each buyer and each seller can only conclude one trade in each period. As there are 10 sellers and 7 buyers, several sellers will not trade in each period.

4. Following the trading phase each seller who has concluded a trade determines which product quality he will supply. The seller is not obliged to supply the product quality desired by his buyer. Once every seller has 
chosen a product quality each participant's earnings in the current period are determined. After this the next period starts.

The points gained from all 15 periods will be summed up at the end of the experiment, exchanged into Swiss Francs and paid together with your endowment in cash.

\section{The Experimental Procedures in Detail}

There are 7 buyers and 10 sellers in the experiment. You are a seller throughout the whole experiment. During the experiment you will enter your decisions on a computer screen. In the following we describe in detail how you can make your decisions in each period.

\section{The Trading Phase}

Each period starts with a trading phase. During the trading phase each buyer can conclude a trade with a seller. In order to do this the buyers can submit offers to the sellers. As a seller you can - in each period - accept one of the offers. During the trading phase you will see the following screen:

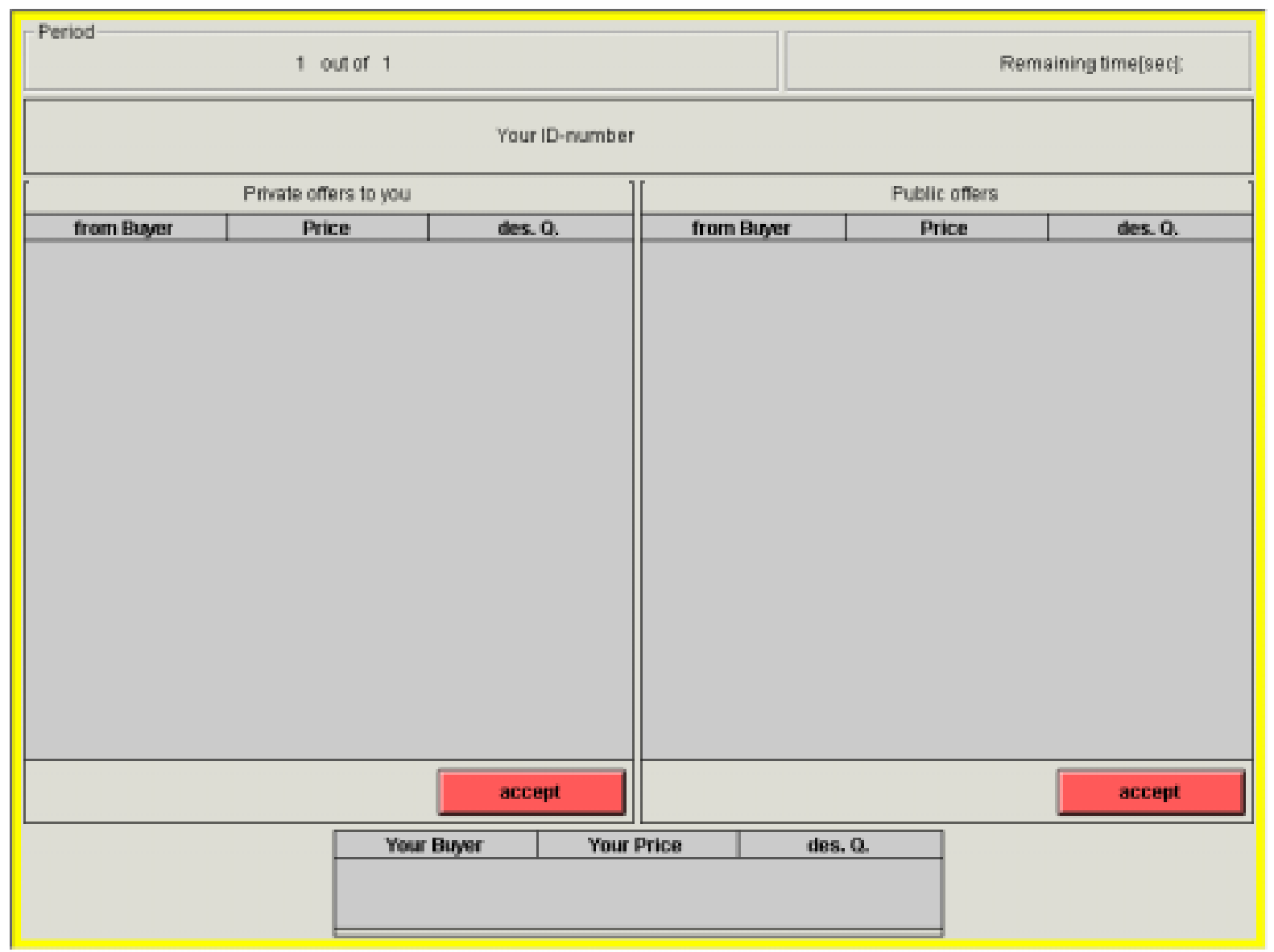

- In the top left corner of the screen you see in which period of the experiment you are. In the top right corner of the screen you see the remaining time in the current trading phase, displayed in seconds. The trading phase in each period lasts 3 minutes (=180 seconds). When this time is up the trading phase is over. Hereafter, no further offers can be submitted or accepted for this period.

- Once the above screen is displayed the trading phase starts. As a seller you can now accept offers submitted by the buyers. There are two types of offers which you can accept:

- Private offers to you

Each buyer has the opportunity to submit private offers to you. You alone will be informed about these offers and you alone can accept them. No other seller or buyer is informed about these offers. 
If you receive private offers, they will appear on the left side of your screen, below the header "Private offers to you". The offer of a buyer contains the following information: the identification number of the buyer who submitted the offer, the price which he offers for the product and which product quality he desires. If you want to accept a private offer, you click first on the respective row in which the offer is displayed. When you do this, the offer will be highlighted. If you are sure you want to accept the offer you then click on the button "accept" which you find at the bottom of the screen. As long as you do not click "accept" you can alter your choice.

\section{- Public offers}

Each buyer also has the possibility to submit public offers. All sellers are informed about these offers and any seller can accept them. If a buyer submits a public offer it appears on the right side of your screen, below the header "Public offers". The offer of a buyer again contains the identification number of the buyer who submitted the offer, the price which he offers for the product and which product quality he desires. This information is also displayed to all other sellers and all buyers. If you want to accept a public offer you follow the same procedures as with private offers. You click first on the respective row in which the offer is displayed. When you are sure that you want to accept the offer you click on the button "accept" which you find at the bottom right corner of the screen. As long as you do not click "accept" you can alter your choice.

- As soon as you have pressed the ,accept“ button you will see which offer you have accepted in the bottom row of your screen.

- $\quad$ Each seller can conclude at most one trade in each period. Once you have accepted one offer you cannot accept any further offers.

\section{All buyers have to observe the following rules when submitting trade offers:}

- The price offered by the buyer must be between 0 and 100 :

$$
0 \leq \text { price } \leq 100
$$

- $\quad$ The desired quality of the buyer must be between 1 and 10 :

$$
1 \leq \text { desired quality } \leq 10
$$

- Each buyer can - in each period - submit as many private and public offers as he wishes. Each offer submitted by a buyer can be accepted at any time during the trading phase.

- Each buyer can conclude at most one trade in each period. Once an offer of a buyer has been accepted he will be informed about which seller accepted the offer. As each buyer can conclude only one trade in each period all other offers of the buyer will automatically be cancelled. Also, he cannot submit any further offers.

- Once all 7 buyers have concluded a trade or after 3 minutes have elapsed, the trading phase is over.

- No buyer is obliged to submit offers, and no seller is obliged to accept an offer.

\section{Determination of the Actual Product Quality}

- Following the trading phase, all sellers who have concluded a trade determine which product quality they supply to their buyers. The product quality desired by your buyer is not binding for you as a seller. You can exactly choose the quality desired by your buyer, but also a higher or lower product quality. If you have concluded a trade during a trading phase, the following screen will appear. Here, you have to enter the product quality: 


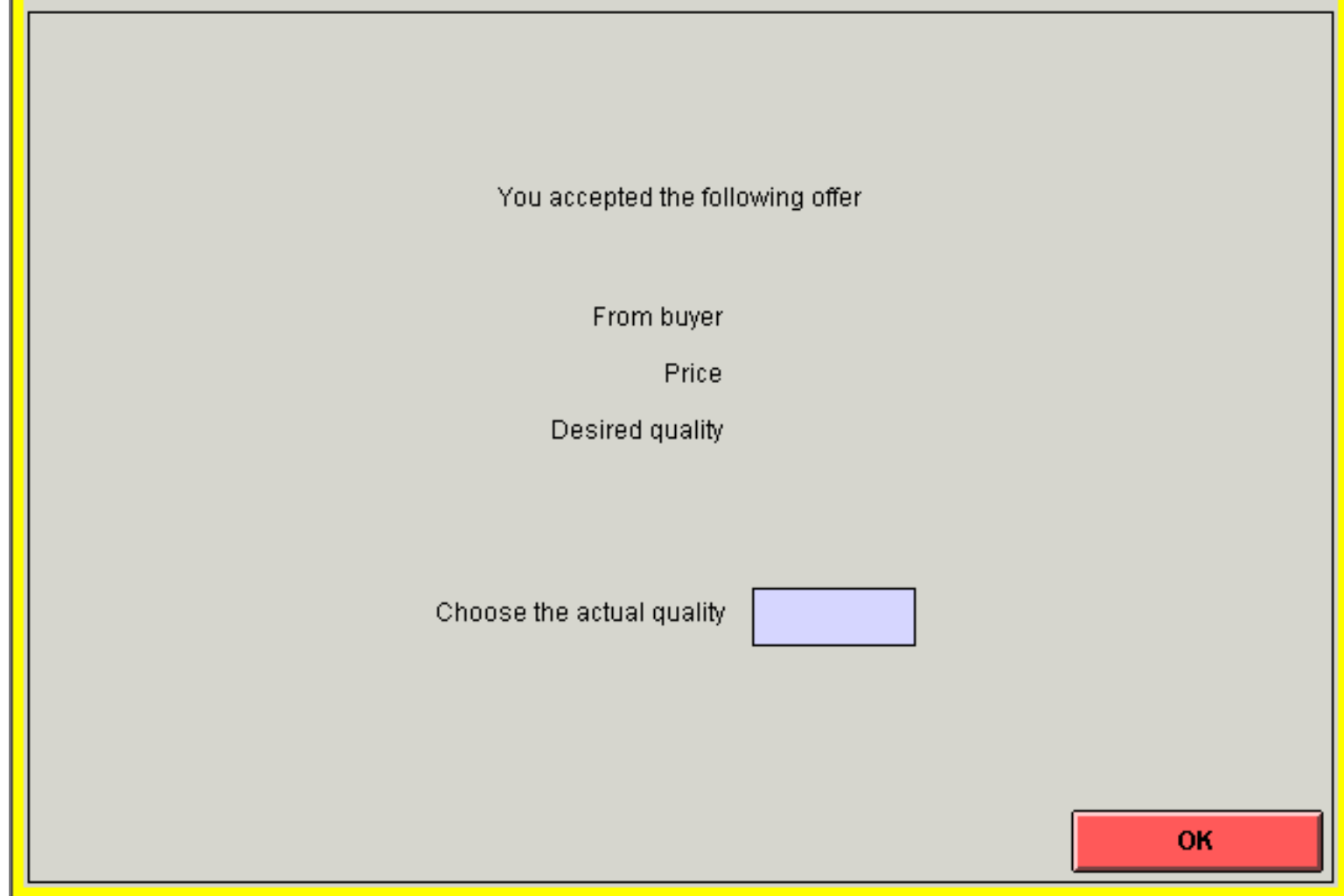

In order to choose the actual product quality, you enter the value for the quality in the field "Choose the actual quality" and press the "OK" button to confirm your choice. As long as you have not pressed "OK" you can alter your choice.

- $\quad$ The product quality you choose must be an integer between 1 and 10 :

\section{$1 \leq$ product quality $\leq 10$}

\section{How are the Incomes calculated?}

\section{$\underline{\text { Your income }}$}

- If you have not concluded a trade during a trading phase you receive an income of $\mathbf{5}$ points in that period.

- If you have accepted an offer your income depends on the price you accepted and the product quality you choose to deliver. Your income is calculated as follows:

\section{Your income $=$ Price - production costs}

- Your production costs are higher, the higher the quality of the product you chose to deliver. The production costs for each product quality are displayed in the table below:

\begin{tabular}{|l|l|l|l|l|l|l|l|l|l|l|}
\hline Product quality & 1 & 2 & 3 & 4 & 5 & 6 & 7 & 8 & 9 & 10 \\
\hline Production costs & 0 & 1 & 2 & 4 & 6 & 8 & 10 & 12 & 15 & 18 \\
\hline
\end{tabular}


- Your income is therefore higher, the lower the product quality. Further, your income is higher, the higher the price.

\section{The income of your buyer:}

- If a buyer does not conclude a trade during a trading phase he receives an income of 0 points in that period.

- If one of his offers is accepted, his income depends on the price he offered and the product quality. The income of your buyer will be determined as follows:

\section{Income of your buyer $=10 *$ product quality - price}

- As you can see from the above formula the income of your buyer is higher, the higher the product quality actually supplied by you. At the same time his income is higher, the lower the price he paid for the product.

The income of all buyers and sellers are determined in the same way. Each buyer can therefore calculate the income of his seller and each seller can calculate the income of his buyer. Further, each buyer and each seller is informed about the identification number of his trading partner in each period.

Please note that buyers and sellers can incur losses in each period. These losses have to be paid from the initial endowment or from earnings made in other periods.

You will be informed about your income and the income of your buyer on an "income screen". On the screen (see below) the following will be displayed:

- Which buyer you traded with

- Which price he offered

- The desired quality of your buyer

- The product quality actually chosen by you

- The income of your buyer in this period

- Your income in this period.

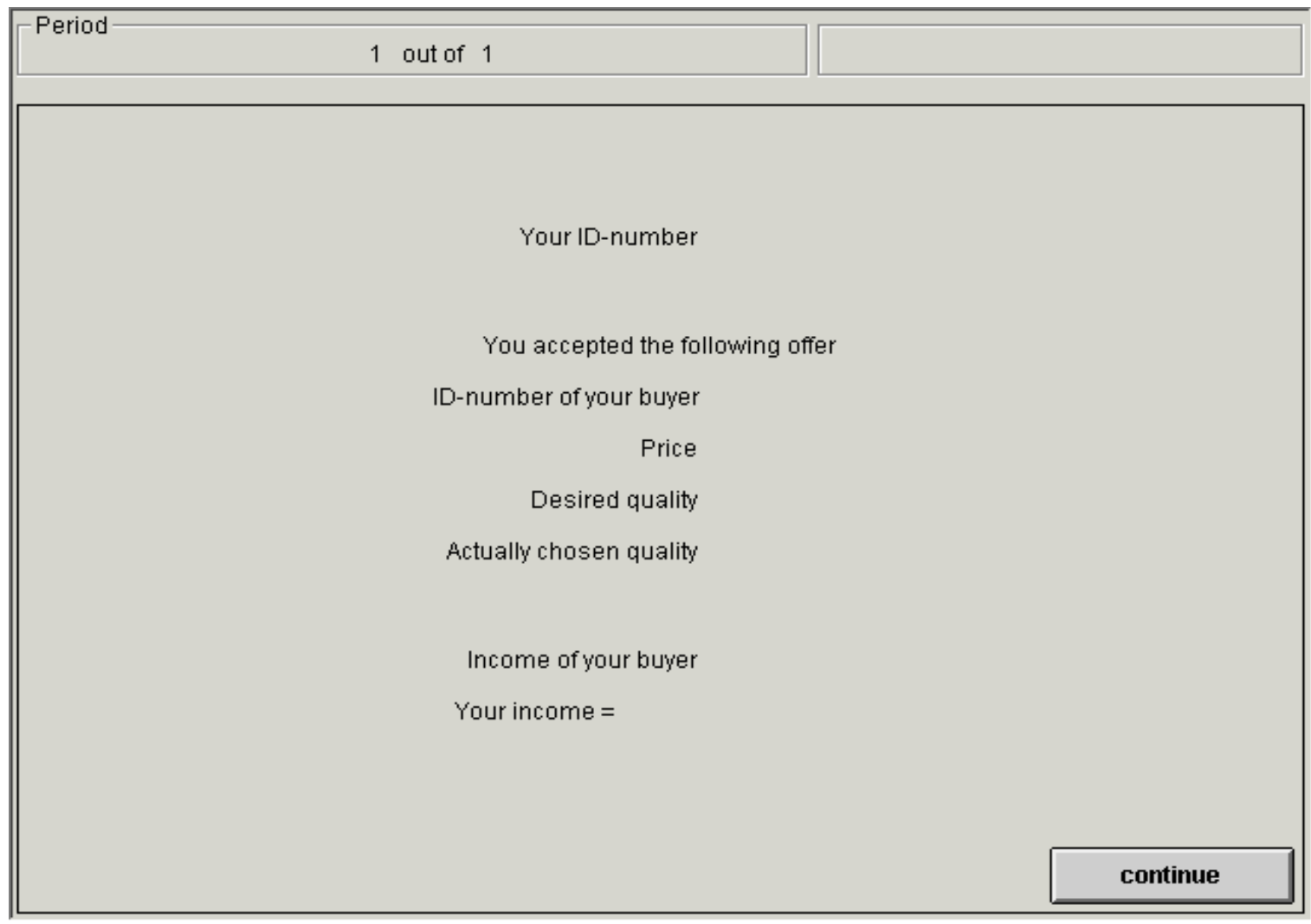


Please enter all the information in the documentation sheet supplied to you. After the income screen has been displayed, the period is over. Thereafter the trading phase of the following period starts. Once you have finished studying the income screen pleas click on the "continue" button.

The buyers also see an income screen, which displays the above information. They see the ID of their trading partner, the price, the desired and the supplied product quality as well as both incomes.

The experiment will not start until all participants are completely familiar with all procedures. In order to secure that this is the case we kindly ask you to solve the exercises below.

In addition we will conduct 2 trials of the trading phase, so that you can get accustomed to the computer. During the trial phases no money can be earned. After the trial phases we will begin the experiment, which will last for 15 periods.

\section{Control Questionnaire}

Please solve the following exercises completely. If you have questions ask the experimenter.

\section{Exercise 1}

You did not accept an offer during a trading phase. What is you income in this period?

$$
\text { Your income }=
$$

\section{Exercise 2}

You accepted an offer with a price of 30 and a desired quality of 9 . You supplied an actual quality of 8.

Your income $=$

Income of your buyer $=$

\section{Exercise 3}

You accepted an offer with a price of 60 and a desired quality of 9. You supplied an actual quality of 4.

Your income $=$

Income of your buyer $=$

\section{Exercise 4}

You accepted an offer with a price of 40 and a desired quality of 2. You supplied an actual quality of 5.

Your income $=$

Income of your buyer $=$

\section{Exercise 5}

You accepted an offer with a price of 30 and a desired quality of 6 . You supplied an actual quality of 6.

Your income $=$

Income of your buyer $=$

\section{Exercise 6}

A buyer has made several offers during a trading phase. None of these offers has been accepted by a seller. What is the income of the buyer in this period?

Income of buyer $=$

If you have finished the exercises we recommend to look again at the exercises and the solutions provided. After this please think about the decisions you want to make during the experiment. 


\section{Documentation sheet: Seller}

This documentation sheet is meant for your orientation. Please complete the respective row in each period.

\begin{tabular}{|c|c|c|c|c|c|c|}
\hline period & $\begin{array}{l}\text { ID of your } \\
\text { buyer }\end{array}$ & price & $\begin{array}{l}\text { desired } \\
\text { quality }\end{array}$ & $\begin{array}{c}\text { actual } \\
\text { quality }\end{array}$ & $\begin{array}{l}\text { income of } \\
\text { your buyer }\end{array}$ & your income \\
\hline 1 & & & & & & \\
\hline 2 & & & & & & \\
\hline 3 & & & & & & \\
\hline 4 & & & & & & \\
\hline 5 & & & & & & \\
\hline 6 & & & & & & \\
\hline 7 & & & & & & \\
\hline 8 & & & & & & \\
\hline 9 & & & & & & \\
\hline 10 & & & & & & \\
\hline 11 & & & & & & \\
\hline 12 & & & & & & \\
\hline 13 & & & & & & \\
\hline 14 & & & & & & \\
\hline 15 & & & & & & \\
\hline
\end{tabular}

